\title{
Midlatitude Cirrus Clouds Derived from Hurricane Nora: A Case Study with Implications for Ice Crystal Nucleation and Shape
}

\author{
Kenneth Sassen ${ }^{1,2}$, W. Patrick Arnott ${ }^{3}$, David O'C. Starr ${ }^{4}$, \\ Gerald G. Mace ${ }^{1}$ Zhien Wang ${ }^{1,5}$, and Michael R. Poellot ${ }^{6}$
}

1. Department of Meteorology, University of Utah, Salt Lake City, Utah

2. Current Affiliation: University of Alaska Fairbanks, Fairbanks, Alaska

3. Desert Research Institute, Reno, Nevada

4. NASA Goddard Space Flight Center, Greenbelt, Maryland

5. Current Affiliation: University of Maryland Baltimore County, Baltimore, Maryland

6. Atmospheric Sciences Department, University of North Dakota, Grand Forks, North Dakota

Corresponding author: Kenneth Sassen, 135 S 1460 E (819 WBB), University of Utah, Salt Lake City, Utah 84112. Email: ksassen@met.utah.edu. 
Address after April 2002: P. O. Box 757320, Geophysical Institute, University of Alaska Fairbanks, Fairbanks, Alaska 999775. Email: ksassen@gi.alaska.edu 


\section{ABSTRACT}

Hurricane Nora traveled up the Baja Peninsula coast in the unusually warm El Nino waters of September 1997, until rapidly decaying as it approached Southern California on 24 September. The anvil cirrus blowoff from the final surge of tropical convection became embedded in subtropical flow that advected the cirrus across the western US, where it was studied from the Facility for Atmospheric Remote Sensing (FARS) in Salt Lake City, Utah. A day later, the cirrus shield remnants were redirected southward by midlatitude circulations into the Southern Great Plains, providing a case study opportunity for the research aircraft and ground-based remote sensors assembled at the Clouds and Radiation Testbed (CART) site in northern Oklahoma. Using these comprehensive resources and new remote sensing cloud retrieval algorithms, the microphysical and radiative cloud properties of this unusual cirrus event are uniquely characterized.

Importantly, at both the FARS and CART sites the cirrus generated spectacular optical displays, which acted as a tracer for the hurricane cirrus, despite the limited lifetimes of individual ice crystals. Lidar depolarization data indicate widespread regions of uniform ice plate orientations, and in situ particle replicator data show a preponderance of pristine, solid hexagonal plates and columns. It is suggested that these unusual aspects are the result of the mode of cirrus particle nucleation, presumably involving the lofting of sea-salt nuclei in thunderstorm updrafts into the upper troposphere. This created a reservoir of haze particles that continued to produce halide-saltcontaminated ice crystals during the extended period of cirrus cloud maintenance. The inference that marine microbiota are embedded in the replicas of ice crystals collected over the CART site points to the longevity of marine effects. Various nucleation scenarios proposed for cirrus clouds based on this and other studies, and the implications for understanding cirrus radiative properties on a global scale, are discussed. 


\section{Introduction}

Cirrus clouds are formed through a variety of weather processes that inject water vapor into the upper troposphere, which in turn suffers dehydration through the subsequent precipitation of the ice particles produced during cirrus growth and maintenance (Sassen 2002a). Since cirrusproducing weather patterns may vary significantly with season and latitude (Sassen and Campbell 2001), it is reasonable to assume that basic cirrus properties will depend substantially on geography. For example, synoptic scale disturbances associated with jet streams would be primarily responsible for cirrus at most midlatitude locations, whereas opportunities to study the cirrus cloud blowoff from organized tropical convection would be infrequent. Nonetheless, although a minor contributor to midlatitude cirrus, such tropical cirrus are abundant in regions of the globe that, unfortunately, generally lack sophisticated remote sensing or in situ research capabilities.

A rare opportunity to comprehensively study cirrus derived from tropical convection occurred near the end of September 1997, as hurricane Nora swept up the Baja Peninsula coast, nurtured by the unusually warm El Nino waters in the eastern Pacific Ocean. After crossing the Baja peninsula as a hurricane on the morning of 25 September, Nora entered the southwestern US at 2100 UTC on the same day as a tropical storm. Total storm rainfall amounts of $10-15 \mathrm{~cm}$ were common in southern Arizona, while Death Valley, California, received $2.8 \mathrm{~cm}$. Considerable damage to agriculture in Arizona, widespread power outages in California, and damage to forests in the mountains of southern Utah were attributed to this storm. Meanwhile, the decaying depression ejected inland a massive cirrus cloud shield that would soon traverse much of North America. Over this period the cirrus would be studied from the Facility for Atmospheric Remote Sensing (FARS, Sassen et al. 2001) in Salt Lake City, Utah, and the Southern Great Plains Clouds and Radiation Testbed (SGP CART, Stokes and Schwartz 1994) site near Lamont, Oklahoma, where serendipitously a major cloud Intensive Observation Period (IOP) supported by aircraft was taking place. Participating 
instrumentation included polarization and Raman lidars, a millimeter-wave Doppler radar, and a variety of radiometers.

An interesting aspect of this tropical cirrus incursion into the continental US is that spectacular optical displays were associated with the cirrus observed at both the FARS and SGP CART sites (and likely elsewhere). The components included the common $22^{\circ}$ halo with tangent arcs, parhelia of $22^{\circ}$ and $120^{\circ}$, and a parhelic circle. However, assuming, for example, that $200 \mu \mathrm{m}$-diameter plate or thick-plate crystals contributed to the displays, the corresponding $0.1-0.2 \mathrm{~m} \mathrm{~s}^{-1}$ fallspeeds (Pruppacher and Klett 1995) indicate that such particles would fall through a cloud depth of one kilometer in a 1.5 - 3-h period. Thus, there is little question that the entire population of ice crystals was replaced (many times over) during the cirrus transport to the central US. Yet, a similar halo/arc complex was observed over the about 30-h period between the observations at the FARS and SGP CART sites.

We consider it important to account for this persistence in optical displays, for it suggests that cirrus ice crystal shape (and hence radiative properties) displays a dependence on the cloud formation mechanism, or more fundamentally, on the manner of nucleation and the ice crystal chemistry during subsequent growth. Current knowledge indicates that cirrus particle formation occurs predominantly through the freezing in updrafts of haze particles derived from cloud condensation nuclei CCN within the homogeneous freezing domain at temperatures $<\sim-38^{\circ} \mathrm{C}$ (Sassen and Dodd 1988; Pruppacher and Klett 1995), although the relative role played by ice nuclei IN is still unclear (DeMott et al. 1998). Midlatitude cirrus cloud particle-forming $\mathrm{CCN}$ are believed to be usually associated with inorganic ionizable salts such as ammonium sulfate, bisulfate, and nitrate, or, alternatively, aqueous sulfuric acid droplets (Tabazadeh and Toon 1998; Chen et al. 2000). The ammonium sulfate particles commonly present in the upper troposphere may be derived either from the boundary layer or the 
stratosphere after sulfuric acid droplet neutralization via ammonium gas absorption (Sassen et al. 1995).

However, it is apparent that the majority of documented cirrus studies reflect a midlatitude continental bias, suggesting that the major climatic impact (in terms of global coverage) of $\mathrm{CCN}$ convectively derived from the surface of the oceans is under appreciated. These nuclei involve mainly chloride salts of sodium and magnesium, and other trace substances. It has been shown in the laboratory that sea salt nuclei act as a contaminant to ice crystal growth after nucleation, thereby affecting ice crystal morphology (Finnegan and Pitter 1997). After examining the Nora case in terms of the synoptic setting and advanced remote sensing and in situ measurements, we consider the hypothesis that cirrus cloud content and radiative properties are affected by the cloud forming particles that are brought to cirrus cloud altitudes by various weather processes.

\section{Instrumentation}

This case study is unique in that the same cirrus cloud system was studied from two advanced remote sensing facilities about 1400-km and 1-day apart. The first site, FARS, is located at $40^{\circ} 49^{\prime} 00^{\prime \prime} \mathrm{N}$ and $111^{\circ} 49^{\prime} 38^{\prime \prime} \mathrm{W}$, while the SGP CART site is at $36^{\circ} 36^{\prime} 18^{\prime \prime} \mathrm{N}$ and $97^{\circ} 26^{\prime} 06^{\prime \prime} \mathrm{W}$. Because a major cloud IOP was taking place at the CART site, much of the instrumentation normally stationed at FARS was transported to the CART site during this period. A thorough description of FARS equipment has recently been provided in Sassen et al. (2001), so only brief descriptions of the lidars are given below.

Remaining at FARS was the Cloud Polarization Lidar (CPL), which is based on a ruby $(0.694 \mu \mathrm{m})$ laser transmitter with a $1.5 \mathrm{~J}$ output and a pulse repetition frequency of $0.1 \mathrm{~Hz}$. The backscattered powers in the planes of polarization orthogonal and parallel to the (vertically polarized) laser are digitized at a 7.5-m range resolution, from which linear depolarization ratios $(\delta)$ are derived. Although normally vertically pointing, the lidar table is 
manually steerable $\sim \pm 5^{\circ}$ from the zenith direction to identify the backscattering anisotropy caused by horizontally oriented ice crystals, and also to unambiguously identify liquid cloud layers (Sassen and Benson 2001). The mobile Polarization Diversity Lidar (PDL) deployed at the CART site is a considerably more sophisticated dual-wavelength $(0.532$ and $1.06 \mu \mathrm{m})$ device based on a Nd:YAG laser transmitter with $0.35 \mathrm{~J}$ outputs in each color and a $10-\mathrm{Hz}$ pulse rate. Data digitization is accomplished at range intervals down to $1.5 \mathrm{~m}$. Although the dual receivers (one for each wavelength) also measure $\delta$ values, during the supporting aircraft mission data were only collected in the $0.532 \mu \mathrm{m}$ channels. Moreover, because of pilot eye safety concerns, no scanning operations were conducted even though the lidar is fully scannable.

Permanent equipment utilized here from the SGP CART site include the Millimeter-wave Cloud Radar (MMCR) and the CART Raman lidar. The MMCR is an especially-designed, vertically-pointing, K-band $(9.6 \mathrm{~mm})$ Doppler radar that is uniquely suited to detect cirrus clouds (Moran et al. 1998). The range resolution was $75-\mathrm{m}$, and the calibration of the equivalent radar reflectivity factor $Z_{\mathrm{e}}\left(\mathrm{mm}^{6} \mathrm{~m}^{-3}\right)$ is considered to be better than $2 \mathrm{~dB}$ based on radar intercomparison research. The advanced design of the CART Raman lidar has been described in Goldsmith et al. (1998), and includes several elastic and inelastic channels for molecular nitrogen and water vapor, particle backscattering and depolarization. The ability to relate the retrieved nitrogen concentrations to those derived from sounding-based air density profiles allows this system to inherently determine the extinction coefficients caused by cirrus cloud particles. However, the much higher resolution PDL is relied on here to provide the lidar returned power and depolarization displays.

The supporting Citation aircraft was provided by the University of North Dakota (UND), and has a sufficient ceiling altitude to reach most midlatitude cirrus cloud tops. It was equipped with a standard set of parameter of state, vertical motion, and cloud microphysical probes, the latter 
including the 2D-C and FSSP. For this cloud IOP, it also carried an ice crystal replicator provided by the Desert Research Institute (Arnott et al. 1994). The aircraft was directed from the ground by personnel that provided updates on cloud conditions based on real-time remote sensor displays. The mission consisted basically of a series of step-up or step-down legs combined with Eulerian spirals to obtain vertical profiles of cloud content as close to the CART site as possible. The horizontal legs (along or into the prevailing wind direction) were $10-20 \mathrm{~km}$ in length, whereas the spiral ascents/descents were usually $<10 \mathrm{~km}$ in diameter: both the edges of the legs and spirals were anchored vertically over the CART site.

In view of the labor intensive analysis of the replicator data (before the tape ran out at 1912 UTC), the goal was to obtain representative images of all crystal types observed in a nominal 10-s time interval, corresponding to $\sim 1.4$ $\mathrm{km}$ of cloud sample. Much of this analysis can be accessed on the web site, http://www.dri.edu/Projects/replica/DOE.ARM/doearm97iop/09_26_97case 109_26_97case.html, which supplements the data given in this paper. The 10$s$ intervals were usually adequate to count and size a representative ensemble of crystals, whereas details of the size spectra begin to be lost on longer time intervals. The web site also provides size spectra and habit decomposition for the various in situ instruments.

\section{Synoptic Weather Setting}

The cirrus clouds observed on 25 September over northern Utah and on 26 September over Oklahoma were associated with upper tropospheric outflow from hurricane Nora and its remnants. Hurricane Nora developed rapidly from a tropical depression over the eastern Pacific on 16 September and deepened into a tropical storm a day later, and finally into a hurricane on 18 September. The system reached peak intensity of $60 \mathrm{~m} \mathrm{~s}^{-1}$ with a central pressure of $950 \mathrm{mb}$ over the anomalously warm El Nino waters $\left(29^{\circ}-30^{\circ} \mathrm{C}\right)$ near $17^{\circ} \mathrm{N}$ and $108^{\circ} \mathrm{W}$. Ahead of a broad, nearly stationary trough in the 
middle troposphere along $125^{\circ} \mathrm{W}$ on 23 September, there was southerly flow at all levels from the ITCZ northward into the western mountains of the North American continent. Another prominent feature of the synoptic setting was the middle tropospheric ridge along the spine of the Rocky Mountains from Mexico into southern Canada. This pattern resembled a weak blocking ridge.

Hurricane Nora became entrained in the southerly flow and accelerated northward along the Baja Peninsula on 23 September. The evolution of the large-scale meteorology during this period is shown in Fig. 1, derived from the NCEP reanalysis (Kalnay et al. 1996). On 24 September, the lower tropospheric circulation associated with Nora, clearly visible in the satellite imagery (top panels, Fig. 2), was not well resolved by the NCEP reanalysis (top panels, Fig. 1). However, the large-scale vertical motion at $300 \mathrm{mb}$ shows a broad swath of upward motion associated with upper tropospheric divergence and the large-scale tropical circulation in which Nora was embedded. Values larger than $3 \mathrm{~cm} \mathrm{~s}^{-1}$ were analyzed. During this period, as Nora transited northward along the Baja coast, the cirrus outflow from the weakening system advected into northern Mexico, southern Arizona and New Mexico. The outflow is particularly evident in the NCEP upper tropospheric humidity field where a corresponding belt of enhanced humidity extends into east Texas at 1200 UTC 24 September.

On 25 September, Nora turned northeastward over the Baja peninsula and the circulation appeared to become disorganized (middle panels, Fig. 2). The upper tropospheric vertical motion that resulted in extensive cirrus outflow during the previous day waned somewhat, but then intensified by 1200 UTC 25 September with peak values of $7 \mathrm{~cm} \mathrm{~s}^{-1}$ over southern California. The NCEP reanalysis suggests and satellite imagery confirms that a cirrus shield was injected into the upper troposphere within and downstream of this region of ascent. Heavy precipitation was observed over the desert Southwest of the US during the following 24 hours. By 1800 UTC 25 September, the associated cloud shield covered much of the intermountain 
western US and extended eastward into Colorado and New Mexico. The 500 $\mathrm{mb}$ ridge axis was now oriented north-south along $\sim 103^{\circ} \mathrm{W}$. At this time, cirrus were being observed by ground-based remote sensors at the University of Utah FARS site (see Section 4) in a layer based at approximately $8 \mathrm{~km}$ at 1700 UTC. The layer progressively thickened until it became optically thick enough to be visually identified as altostratus and attenuate the lidar signals after 2000 UTC. It is worth noting the good correspondence between the region of high relative humidity resolved by the NCEP analysis (1200 UTC) and the upper tropospheric clouds in the satellite imagery (0600 and 1800 UTC) on 25 September. We find that the cirrus were largely formed in the ascending air over the intermountain western US but apparently advected into a region of large-scale descent where the clouds thinned and eventually dissipated as they approached the ridge axis.

The pattern in the middle and upper troposphere became somewhat more progressive on 26 September as a short wave trough approached the Pacific Northwest. The ridge axis at $500 \mathrm{mb}$ began to tilt and then move eastward. By 1200 UTC, the 500-mb ridge axis passed northeastward through the Oklahoma panhandle. The ARM site was still in weak northwesterly flow of $\sim 25 \mathrm{~m} \mathrm{~s}^{-1}$ at $300 \mathrm{mb}$ at midday on 26 September indicating that the ridge axis at this level was still to the west. As the pattern deamplified and became progressive, the reanalysis suggests that the ascent weakened in the upper troposphere, although an extensive region downwind of the vertical motion maximum continued to exhibit elevated values of upper tropospheric relative humidity (Fig. 1).

Three-hourly radiosonde observations at the SGP CART site (Fig. 3) show increasing upper tropospheric moisture in a layer near $11 \mathrm{~km}$ beginning at 0600 UTC on 26 September, later bifurcating into two layers of enhanced humidity around $9 \mathrm{~km}$ and from 11 to $12 \mathrm{~km}$ at $1800 \mathrm{UTC}$, and then developing into a deep moist layer from 8 to $12.5 \mathrm{~km}$ by 0000 UTC. A northsouth oriented cirrus band, located just downstream of the ridge axis, approached the CART site at $\sim 1800$ UTC (Fig. 4). Contrail formation was 
observed within the cloud band and in the moist westerly flow to the west of the main cirrus cloud band (Duda et al., 2001). Over the next three hours, while the Citation conducted a mission in the cirrus band and ground-based remote sensors operated from below, the north-south oriented band progressed slowly eastward and passed over the CART site. By 0000 UTC 27 September, the ridge axis passed to the east as the flow in the upper troposphere turned westerly (Fig. 3). Interestingly, the reanalysis data suggests that large scale descending air persisted in the upper troposphere during this entire cloud event. A similar finding was reported by Starr and Wylie (1990) in "ridge-crest" cirrus.

It is of note that the middle tropospheric air over the CART site on 26 September was not Nora-derived. A stable layer resembling an elevated frontal zone (region of closely spaced isentropes in Fig. 3) occurred at about the $7 \mathrm{~km}$ level after 1200 UTC on 26 September (higher earlier). Very weak winds were found in the very dry air below this level. The overrunning Nora air is characterized by reduced static stability (wider separation of the isentropes in Fig. 3), especially from 11 to $12 \mathrm{~km}$ at 1800 UTC and from 10 to 12 $\mathrm{km}$ at 0000 UTC on 27 September, and is capped by a more stable region that extends from $12 \mathrm{~km}$ to about $16 \mathrm{~km}$ where the lapse rate becomes distinctly stratospheric.

\section{The FARS Dataset}

Figure 5 provides an overview of the cirrus cloud conditions observed from FARS over the 1600-2030 UTC observation period on 25 September 1997. During this time, the leading edge of the hurricane cirrus cloud shield moved rather rapidly over the FARS site from the south (Fig. 2). Shown at top are fisheye photographs of cloud conditions taken at the indicated times (in UTC). CPL height versus time displays are given below in terms of relative returned parallel-polarized laser power (based on a logarithmic gray scale), with the local 0000 UTC 26 September temperature (solid line) and dew point profiles at right, and linear depolarization ratios (see color $\delta$ scale at right). 
Beginning with broken cirrus fibratus coverage, the cirrus layer can be seen to gradually thicken and become dense enough by $\sim 2000$ UTC to have transformed into altostratus. (Note the loss of sharpness of the solar disk in the 2030 UTC fisheye at upper right, and the strongly attenuated lidar signals). Originally about $2-\mathrm{km}$ thick, the layer developed several deep particle fallstreaks with tops up to $\sim 11.5 \mathrm{~km}$ MSL. This active precipitation produced a gradually descending cloud base until $\sim 1900$ UTC, when the $6.5-\mathrm{km}$ base reached a relatively dry subcloud layer. At this time, particle evaporation promoted 0.5-0.7 $\mathrm{km}$ deep cirrus mammatus structures below the usual cloud base altitude (Sassen 2002a). These features are in agreement with the satellite imagery, which shows the cirrus shield leading edge advecting rapidly over FARS on the afternoon of 25 September.

The $\delta$ value display at the bottom of Fig. 5 reveals a wide range of cloud microphysical conditions, judging from the near-zero to the maximum $\sim 0.5$ spread of values. The central part of the layer displays $\delta \approx 0.2$, which are somewhat lower than usual for midlatitude cirrus in the $-20^{\circ}$ to $-25^{\circ} \mathrm{C}$ temperature range (Sassen and Benson 2001), but consistent with those values for cirrus that produce halo displays (Sassen et al. 2002). On the other hand, the extended regions displaying $\delta<0.05$ indicate the presence of horizontallyaligned planar ice crystals, as was confirmed by occasionally tipping the lidar a few degrees off the zenith direction. Note how the lowest $\delta$ values correspond to the strongest lidar backscatter, particularly near cloud base during the cirrostratus-to-altostratus cloud transition. Also note that depolarization generally increases in the region just above cloud base, presumably due to the effects of particle evaporation (i.e., producing sizes too small to orient) and or/aggregation.

An unusual (i.e., for FARS) variety of halo and arc features was observed, although their types and intensities varied a over time. The middle fisheyes at top of Fig. 5 indicate the presence of the $22^{\circ}$ halo, upper 
tangent arc, and segments of the parhelic circle (see also Sassen 1999). Also observed were $22^{\circ}$ and $120^{\circ}$ parhelia, and a vague upper Parry arc. It is interesting to note that the most brilliant optical displays were observed at about 1800 and from 1930-2000, times that correspond to the most abundant $\delta<0.05$ values in the cirrus before the altostratus advected overhead. Such optically dense clouds weaken or destroy optical displays as seen from the ground because of photon multiple scattering (Tränkle and Greenler 1987).

\section{The SGP CART Dataset}

\section{a. Overview}

In addition to lidar depolarization measurements by the PDL at the CART site, the additional radar and aircraft data available from this IOP campaign make this a particularly comprehensive cirrus case study. The local satellite imagery in Fig. 4 derived from expanded GOES infrared channel data show the movement of the cirrus over the site over the $1800-2130$ UTC period of supporting aircraft operations. It can be seen that as the main approximately north-south cirrus streak approached from the northwest, a number of small wave-like cirrus structures advected over the CART site until the dense streak arrived at $\sim 2045$ UTC. According to Fig. 2, this cirrus represented the initial tongue of the hurricane-derived cirrus that was entrained into a midlatitude circulation and redirected southward.

A comparison of lidar attenuated backscattering and depolarization (at $0.532 \mu \mathrm{m}$ ) with MMCR radar reflectivities and Doppler velocities over the period of the aircraft mission is provided in Fig. 6. These data reveal a gradually thickening cirrus layer, which may have been optically thick enough to be visually classified as altostratus at $\sim 2045$ UTC, although the limited dynamic range of the PDL detectors may have been responsible for the loss of lidar signals near cloud top at that time. Note that the $60 \%$ relative humidity (with respect to ice) contour in Fig. 3 closely demarcates the observed cloud layer boundaries. The PDL and MMCR have produced 
unusually similar images of the cloud system, although the radar usually under-predicts cloud top heights by a few hundred meters, and misses some of the thinnest cirrus at the beginning of the period. In agreement with the satellite images in Fig. 4, the cirrus initially consisted of separate mesoscale uncinus cirrus (MUC) generating regions (Sassen 2002a), until 1920 when the more continuous and vertically-developed cirrus moved overhead. The radar Doppler velocities (Fig. 6) show evidence for upward motions (red to purple colors) near the heads of the MUCs, followed by precipitation particledominated downward motions, sometimes in excess of $1 \mathrm{~m} \mathrm{~s}^{-1}$, in the deep fallstreak patterns embedded in the main cirrus cloud.

As in the case at FARS, both widespread regions of quite low $\delta$ values and an unusual variety of cirrus cloud optical displays were observed at the SGP CART site. The $\delta<0.1$ are usually found at the tops of the cirrus generating regions, and generally correspond to the periods when the optical displays were most pronounced. Large areas display $\delta \approx 0.15$, and the strongest depolarizations (up to $\sim 0.5$ ) were noted near the bottoms of the dense fallstreaks after 2000 UTC, where the strongest $Z$ indicative of ice crystal aggregates were observed. (Linear depolarization can be expected to increase in aggregates because of the increased shape complexity and the collection of oriented crystals that would otherwise generate specular reflections.) A brilliant $22^{\circ}$ halo, upper and lower tangent arcs, parhelia, and parhelic circle were variably reported by ground observers and the Citation crew. Flight notes indicate that the most brilliant and varied optical displays occurred from $\sim 1930-2000$ UTC, when large regions of $\delta<0.15$ where present. These similarities with the FARS observations, despite the extended $(\sim 30-\mathrm{h})$ period of cloud advection between the two sites, are notable.

In Fig. 7, we add to this evaluation the data provided by the in situ probes on the Citation aircraft. From top to bottom are shown the aircraft flight track, the radial distance of the aircraft from the CART site, and an analysis of 5-s averages of (2D-C probe-detected) ice particle concentration $\mathrm{N}$, 
effective mean diameter $D_{m}$ (based on the image maximum dimension), and ice water content IWC. The Citation altitude track has been superimposed on the lidar $\delta$ value display because it is these data that best conveys information on ice particle shape for comparison to the in situ findings. The IWC data have been derived through two approaches using the 2D-C probe data. The first is described in Wang and Sassen (2002; see next section) and the second (red dots) is a more standard approach based on the NCAR analysis scheme used at UND. Note that the two methods generally agree to better than a factor of 2 .

There is a tendency for both $\mathrm{D}_{\mathrm{m}}$ and IWC to increase with decreasing height, or increasing temperature, which is better shown in Fig. 8. In view of the cirrus coverage variability over the CART site seen in the expanded satellite views of Fig. 4 during the initial broken-cirrus period, it is more appropriate to examine the data collected during the final aircraft spiral ascent and descent from 2025-2055 UTC, when the cirrus was considerably more widespread. The vertical profiles of $\mathrm{N}, \mathrm{D}_{\mathrm{m}^{\prime}}$ and IWC given in Fig. 8 combine the data from the spirals, and 250-m vertical averages of these data quantities are also provided. It is clear that, with exception of the upper cirrus cloud generating region, most of the cirrus have average $N \approx 10-30 \mathrm{~L}^{-1}, \mathrm{D}_{\mathrm{m}} \approx 225 \mu \mathrm{m}$, and IWC $\approx 10-30 \mathrm{mg} \mathrm{m}^{-3}$. The upper kilometer of cirrus, however, has lower IWC and smaller crystals, which may be responsible for the lower $\mathrm{N}$ because the lower size limit $\left(D_{m}=50-100 \mu \mathrm{m}\right)$ of the $2 D-C$ probe was approached in this region. The IWC profile (in logarithmic units) displays strong gradients near cloud top and cloud base from crystal nucleation and evaporation, respectively, and a gradual increase within the body of the layer. These average temperature dependencies reflect the effects of the ice crystal growth and sedimentation rates on cirrus cloud formation, maintenance, and dissipation.

b. Detailed Microphysical Findings 
Described here are expanded views of the PDL displays and in situ data from periods when the replicator device aboard the Citation was functioning (prior to 1912 UTC). The first example from 1832-1845 UTC provides a view of a double-layered cirrus cloud that contains breaking Kelvin-Helmholtz (KH) waves (Fig. 9). As in Fig. 6, the aircraft height is shown at top over the PDL $\delta$-value display, and the aircraft distance from the CART site is given in the panel below. The low lidar $\delta$-values show the presence of horizontallyoriented planar ice crystals along the tops of both cloud layers. The top of the upper layer is convective in appearance, reflecting the presence of numerous cirrus uncinus cell heads. The depolarization in the series of breaking K-H waves is particularly striking, and can be used perhaps to trace the air motions. Figure 10 shows a higher resolution view of the best developed $\mathrm{K}-\mathrm{H}$ wave in terms of relative backscattering and depolarization. It appears that ice crystals from the middle part of the layer $(\delta \sim 0.05-0.1)$ have been drawn up into the breaking wave head, while the more uniformly oriented ice plates $(\delta<0.05)$ from cloud top have been drawn underneath. It is also interesting to find higher $\delta$ values, up to $\sim 0.25$, on the underside of the wave crest. This increase in depolarization could be due to the aerodynamic disorientation of the crystals from turbulence, or alternatively to particle evaporation effects (from dry air mixing) at this part of the breaking wave.

Interestingly, although there is no dramatic wind feature in the 1800 UTC sounding at the level of the K-H waves (Fig. 3), there is an indication of a weak directional shear boundary near $11.0 \mathrm{~km}$ with a speed shear of $\sim 1 \mathrm{~m} \mathrm{~s}^{-1}$ $\mathrm{km}^{-1}$. However, small scale wind features can be highly smoothed during standard operational sonde processing (via Vaisala LORAN winds). There is also some indication of a thin layer of enhanced static stability at about this height (i.e., a lapse rate minima of $6.8^{\circ} \mathrm{C} \mathrm{km}^{-1}$ versus values exceeding $8^{\circ} \mathrm{C} \mathrm{km}$ ${ }^{1}$ at $0.5 \mathrm{~km}$ above and below). 
Unfortunately, because of the cirrus spatial variability encountered by the aircraft at this time (see Fig. 4), the in situ data in Fig. 9 do not closely reflect the local cloud structure observed by the lidar, and the KelvinHelmholtz waves were not sampled. Figure 11 provides a montage of selected photomicrographs of ice crystals on the replicator film for two cloud regions. The first sample corresponds to the penetration of the base of the upper cirrus layer. The initial crystals (top of Fig. 11a) resemble polycrystals or aggregates, which broke apart upon impaction onto the substrate, and single crystals that appear to have rounded crystal forms due to sublimation. Most of the remaining crystals are solid plates and columns with maximum dimensions of $25-75 \mu \mathrm{m}$. At the time of the second sample (Fig. 11b) the aircraft was more $(5-8 \mathrm{~km})$ distant from the lidar site at a height corresponding to the top of the upper cirrus layer. These images also reveal mostly solid, pristine ice crystals spanning the habit range from thin plates to long columns, although their sizes sometimes exceed $100 \mu \mathrm{m}$. Note that just as the columns display a variety of aspect ratios, it is likely that the planar crystals were also of variable thickness. This indicates that the cirrus composition was generally well mixed due to the effects of vertical motions, particle sedimentation, and turbulent mixing. There appear to be fewer radial polycrystals or aggregates. The $2 \mathrm{D}-\mathrm{C}$ data from both regions show $\mathrm{D}_{\mathrm{m}}$ of $\sim 100$ $\mu \mathrm{m}$, with $\mathrm{N}$ and IWC varying from about $5-75 \mathrm{~L}^{-1}$ and $1-10 \mathrm{mg} \mathrm{m}^{-3}$, respectively.

The similar set of data in Figs. 12-13 shows the results of sampling the mesoscale generating region from 1845-1905 UTC, when the aircraft legs were of $\sim 20 \mathrm{~km}$ in length. This classic MUC displays a convective-appearing cloud top, a central body of numerous collected fall streaks, and a tail of virga in an apparently moist layer that has accumulated at the same height as the bottom layer noted just before. Note that the massive S-shaped fall streak pattern suggests a more structured horizontal wind profile than indicated by the soundings (Fig. 3), which could help explain the presence of the breaking $\mathrm{K}-\mathrm{H}$ 
waves in Fig. 9. Lidar $\delta$ values are again low from oriented ice plates along portions of the tops of the upper and lower cloud structures, although much of the central body shows $\delta \approx 0.3$. Microphysically, $\mathrm{D}_{\mathrm{m}}$ of $\sim 100 \mu \mathrm{m}$ and a strong variability in N and IWC are again found in the 2D-C data. The ice crystal casts in Fig. 13 were obtained when the aircraft was nearly overhead, and depict mostly solid pristine plates and columns with 50-150 $\mu \mathrm{m}$ maximum dimensions. As also seen before, although many of the plates display nearly perfect hexagonal perimeters, the $75-\mu \mathrm{m}$ plate at lower right is an uneven hexagon. Note also the long column with rounded ends and linear and elliptical surface designs, and the evidence for shattered radial crystals at the bottom. Finally, as discussed in more detail below, some of the particles have central features ranging from $\sim 5$ to $20 \mu \mathrm{m}$ in diameter.

The final example in Fig. 14 from 1845-1905 UTC depicts the last recognizable MUC before the cirrus layer became continuous and began a sudden deepening. Its structure is similar to that described above, but smaller regions display the low $\delta$ values indicative of oriented plates. The Citation aircraft performed an ascent spiral above the CART site in this case. The 2D-C measured somewhat higher $D_{m}, N$, and IWC as it ascended through the body of the MUC, indicating more active ice particle generation and growth. Radar reflectivities have also increased and Doppler velocities indicate relatively stronger updrafts in the central fall streak (Fig. 6).

The replicator images in Fig. 15 are broken into four intervals as the Citation ascended through the cirrus from 11.4 to $12.2 \mathrm{~km}\left(-43^{\circ}\right.$ to $\left.-49^{\circ} \mathrm{C}\right)$. In the initial sample (Fig. 15a) from $11.4 \mathrm{~km}$, a height that earlier displayed strong oriented plate crystal effects, a number of plate crystals exceeding 100 $\mu \mathrm{m}$ in maximum dimension are present, along with whole and broken mostly-solid columns and plate-like polycrystals or aggregates. Almost all of the plates display either 3-fold symmetry (trigonal plates) or uneven hexagonal shapes: whether such shapes are more or less likely to maintain 
stable orientations is unclear. The next sample (b) shows a large aggregate and stout columns, but fewer large plates. Note the shattered $\sim 100 \mu \mathrm{m}$ plate at bottom right, the bullet-like crystal to the left of the $50 \mu \mathrm{m}$ scale, and the column above with a central elliptical design. Continuing upward, the next sample (c) contains mainly smaller plates, some of which appear to be poorly preserved, and others that have grossly distorted hexagonal perimeters (e.g., top left). The largest plate at center left has been broken on impact, and to the right is a column with tapered ends that resembles a pyramidal crystal. The final sample, from a height near cloud top producing the strongest lidar depolarization, is dominated by long mostly-solid columns and what are apparently plate polycrystals. Some plates with trigonal and hexagonal symmetries are present, but are generally $<100 \mu \mathrm{m}$. The crystal at bottom left has a 4 -fold perimeter and an odd internal design, suggesting cubic symmetry. In general, fragmented radial crystals are now more common in this MUC, which can help explain the higher $\delta$-values, radar reflectivity, and Doppler velocities measured at this time.

As mentioned above, some of the plates and columns display an unusual feature: a central circular or irregular design. Figure 16 provides expanded views of some of these particles, which we suggest contain marine microbes that acted as ice nuclei. We acknowledge that the central markings on many of the crystals probably represent artifacts or circular growth terraces (or pits) on the crystal faces that were preserved in the particle casts: this particle morphology is often noted (see e.g., Sassen and Takano 2000). However, the resemblance of some of the central features to cellular morphology is so strong that biogenic ice nuclei are indicated. Many of the smaller central "dots" have no recognizable features, but are located precisely at the particle center, where the remnants of ice nuclei are to be expected. Also note that any internal central cavity will not be preserved in the replicas, unless it is attached to other cavities that allow the plastic relicator fluid to migrate into a hollow crystal. Usually, the film depth is too thin to allow the 
preservation of the upper crystal face, so normally we are left with a hollow depression in the film after the sublimation of the ice. Any insoluble materials are deposited on the bottom of the particle cast.

Examination of the lidar depolarization displays in Figs. 9, 12, and 14 reveals that the $\delta$ values range from $\sim 0$ to 0.4 , which reflects various crystal shapes and orientations that is not unusual for cirrus (Sassen and Benson 2001), particularly those generating halos (Sassen et al. 2002). The near-zero $\delta$ values are caused by a laser backscattering medium dominated by horizontally oriented plate crystals, and it is apparent that the influence of this backscattering anisotropy diminished over this period as the cirrus cloud system developed. These regions are typically found at and near the tops of the cloud layers, whereas the strongest depolarization occurs near the cloud bases. It appears that the planar crystals are often generated in cloud-top uncinus cells and are able to maintain their orientations in fall streaks up to $\sim 0.5 \mathrm{~km}$ in depth. Thus, the usual gradient in $\delta$ values observed from cirrus layer cloud top to base must reflect basic thermodynamical conditions favorable for the growth of large plates, including such factors as temperature and water vapor supersaturation level. It is probable that plate crystal growth is favored in this case by the relatively high supersaturations, which are required for ice nucleation, at cloud tops. Also of importance is the concentration of nucleated crystals competing for the available moisture supply, which is influenced by the updraft velocity (Lin et al. 2002). The transformation of plates into thick plates and columns occurs under different environments during particle fall, and may be assisted by particle sorting via habit-dependent differences in fallspeeds. Finally, the strongest depolarization measured near cloud bases (see especially Fig. 14) could reflect the effects of particle aggregation, and also crystal evaporation, which makes the plates too small to orient aerodynamically.

Although the position of the aircraft rarely corresponds precisely to the lidar zenith sample volume, the general types of ice crystals replicated can be 
compared to the lidar depolarization data. The preserved crystal shapes show that a wide range of ice crystal aspect ratios, from thin plates to long columns, and radial crystals or aggregates, were indeed sampled in situ. As for the plate crystals, the ability to uniformly orient in space stems from the action of aerodynamic drag forces, which are functions of particle fall speed (i.e., shape, density, and size) and air density (height). The Reynolds number $R e=v d / v$ provides a convenient factor to relate the particle terminal velocity $v$, diameter $d$, and kinematic viscosity $v$ of the fluid. (For ice crystals falling in air, $d$ is an equivalent size usually taken as the particle maximum dimension, and $v$ is proportional to air pressure.) A variety of evidence indicates that stable particle fall attitudes are achieved under the condition $1<\operatorname{Re}<100$. According to current knowledge, $R e=1$ corresponds to $d \approx 200-300 \mu \mathrm{m}$ for plate and thick plate crystals at a typical cirrus cloud pressure of $300 \mathrm{mb}$ (Sassen 1980).

However, it is apparent from Figs. 11, 13, and 15 that few planar ice crystals much larger than $\sim 100 \mu \mathrm{m}$ were collected. [Columnar crystals $>200 \mu \mathrm{m}$ that are certainly large enough to be oriented horizontally are present, but a Parry arc would have been the signature of columns oriented with prism faces parallel to the ground in order to produce lidar specular reflections (Sassen and Takano 2000).] On the other hand, the maximum 2D-C image diameters (not shown) during this period are often 200-300 $\mu \mathrm{m}$, which are (marginally) in line with the earlier research based on light pillar observations (Sassen 1980). Thus the fracturing of planar ice crystals during impaction on the replicator substrate may have effected the results, as can often be seen in the casts of shattered plates of $\sim 100 \mu \mathrm{m}$ diameter (see, e.g., Fig. 15). Moreover, as shown by Sassen and Benson (2001), only a relatively few plates need be horizontally oriented in order to significantly reduce lidar $\delta$ values: for example, about 1 properly oriented plate out of 100 would generate $\delta=0.05$. Nonetheless, the in situ evidence indicates that it is likely 
that ice crystals smaller than previously thought can maintain approximately horizontal orientations. This may be particularly true in the Nora cirrus case, because the fall patterns of the regular solid crystal shapes could be unusually stable. Finally, the visualization of nocturnal light pillars may require very small crystal departures from the horizontal plane relative to zenith lidar depolarization measurements. Thus we conclude that planar ice crystals on the order of 100-200 $\mu \mathrm{m}$ diameter at cirrus altitudes are probably sufficiently large to develop fall attitudes stable enough to be identified by polarization lidar observations.

\section{Retrieved Microphysical and Radiative Properties}

Improving multiple remote sensor algorithms for the estimation of cirrus cloud microphysical and radiative properties hold promise for more accurately characterizing these important cloud quantities from the ground. Here, in order to provide much more continuous vertical information than is possible from aircraft operations, we have taken advantage of these recent developments to convert the remote sensing data into fields of general effective size $D_{g e}$ and IWC (see Fu 1996), and the vertically-integrated quantities of ice water path (IWP), infrared layer emittance $\varepsilon$, and visible cloud optical depth $\tau$. Figure 17 provides the results.

The method used for deriving $\mathrm{D}_{\mathrm{ge}}$, IWC, and IWP relies on the combined analysis of the MMCR $Z_{e}$ and Raman lidar visible extinction coefficient $\sigma\left(\mathrm{km}^{-1}\right)$, as described in Wang and Sassen (2002). It is based on the treatment of cirrus cloud radiative properties developed by $\mathrm{Fu}$ (1996), in which $\sigma$ is parameterized as functions of IWC, $D_{g^{\prime}}$ and two constants at the lidar wavelength. Using the same assumptions regarding ice crystal shape as in $\mathrm{Fu}$ (1996), and further assuming that the Rayliegh approximation is valid and the radar reflectivity of hexagonal ice crystals is equal to that of an equivalent volume ice sphere, $Z_{e}$ can be parameterized approximately as $Z_{e}=$ 
$C^{\prime}\left(\right.$ IWC $\left./ \rho_{\mathrm{i}}\right) \mathrm{D}_{\text {ge }}{ }^{\mathrm{b}}$, where $\mathrm{C}^{\prime}$ and $\mathrm{b}$ are constants based on a modified gamma size distribution. Note that in Wang and Sassen (2002) we have tested the algorithm results against the aircraft data obtained in this case study and found good agreement for spatially consistent data. To derive the $\tau$ and $\varepsilon$ (red) traces in Fig. 17, we have used the combined lidar and infrared radiometer (LIRAD) approach, using PDL backscatter and the FARS coaligned midinfrared radiometer (Comstock and Sassen 2001). The comparison of LIRAD-derived $\tau$ with that provided by the direct analysis of the Raman lidar data shows quite good agreement.

The results in Fig. 17 are in general compliance with those expected for midlatitude cirrus (see Sassen 2002a). The initial $\sim 1.5 \mathrm{~km}$-deep fibratus can be seen to be composed of relatively small $(<\sim 50 \mu \mathrm{m})$ effective particle sizes that produce correspondingly small IWP values, except in the central fallstreak of the final MUC at 1910 UTC. The mostly $\tau<\sim 0.3$ and $\varepsilon<0.4$ before this time are consistent with thin (i.e., bluish-appearing) cirrus. With vertical development, all the derived data quantities increase, and then decrease after the maximum cloud depth is attained. In particular, particle sizes and IWC increase in the upper cloud region, indicating conditions more favorable for active particle growth. Note also how the $\tau \approx 3.0$ and $\varepsilon \approx 0.85$ limits for cirrostratus (Sassen 2002a) are approached when the cirrus cloud reaches its maximum depth at 2045 UTC.

\section{Discussion and Conclusions}

This cirrus cloud case study is rare both because of the comprehensive resources that were used to observe it from two major remote sensing facilities in the western and central US, and the nature of the cirrus itself: midlatitude cirrus that evolved over a period of days out of a hurricane. The convective-derived tropical cirrus soon became maintained by extratropical processes as it advected inland. Simple considerations show that the ice mass 
generated originally over the eastern Pacific Ocean could not persist for long due to particle fallout. Thus, the only long-lasting impact of the initial formation mechanism must be found in the upper tropospheric reservoir of $\mathrm{CCN}$ that was raised from the ocean's surface during strong organized convection. The generation rates of sea salt particles and droplets from the oceans surface (Monahan et al. 1983) are known to be controlled by the wind speed. In addition to the generation of marine aerosols from breaking waves through the bursting bubble mechanism, at wind speeds $>9 \mathrm{~m} \mathrm{~s}^{-1}$ great numbers of spume droplets are created as wave crests are torn apart by the action of the wind. O'Dowd and Smith (1993) reported sea salt CCN concentrations of up to $100 \mathrm{~cm}^{-3}$ at a surface wind speed of $20 \mathrm{~m} \mathrm{~s}^{-1}$ : the particles were characterized by three log-normal size distributions according to the production mechanism, corresponding to number mode radii of 0.1 , 1.0 , and $6.0 \mu \mathrm{m}$. Thus it is indicated that the great surface wind speeds within hurricanes can generate, and loft to high altitudes in thunderstorm updrafts, large quantities of both small and large marine particles. In this case, surface wind speeds of up to $\sim 60 \mathrm{~m} \mathrm{~s}^{-1}$ were associated with hurricane Nora.

Although giant $\mathrm{CCN}$ scavenging through precipitation processes may be an effective sink for many of the lofted marine particles, the remaining $\mathrm{CCN}$ and the decay and evaporation of ice particles represent a potential source of future cirrus cloud particles. The presence of apparent marine biogenic nuclei with diameters up to $40 \mu \mathrm{m}$ at the centers of ice crystal replicas demonstrates the efficacy of this lofting mechanism during spume droplet formation. It also for the first time illustrates that marine microbioto can serve as ice nuclei in cirrus clouds, but since the numbers of such identified particles is relatively small, this mechanism is probably unimportant in the overall scheme of things. Previously, Brier and Cline (1959) showed ocean water to be a source of IN and Saxena (1983) found evidence for the presence of biogenic nuclei in Antarctic coastal clouds. The efficacy of both terrestrial and marine microbes in initiating the ice phase in the laboratory has been 
summarized by Schnell and Vali (1976). The processing of marine boundary layer air by convective clouds has also been shown to generate high concentrations of new aerosol particles in the free troposphere with the aid of photochemistry (Clarke et al. 1998), but such minute particles may not be able to compete effectively with the background of larger cloud-forming nuclei in cirrus. The model study of Ghan et al. (1998) illustrates how sea salt CCN can successfully compete (in droplet clouds) with background populations of sulfate particles.

The concept that basic cloud microphysical and radiative properties may be influenced by the cloud generation mechanism is not new, and differences in some radiative properties have already been shown to exist within the FARS midlatitude cirrus cloud dataset (Sassen and Comstock 2001). In that study, midlatitude synoptic, orographic, and anvil cirrus clouds often had dissimilar properties in terms of their $\tau$-versus- $\varepsilon$ relations and backscatter-toextinction ratios, which can be expected due to the effects of the strengths of typical updrafts, cloud formation temperature, and, importantly, the source of CCN.

In this study we have pointed out that the Nora cirrus cloud shield system contained extensive regions of horizontally-oriented pristine, solid ice crystals, which were effective at generating uncommon optical displays. These ice particles are quite similar to those sampled on the Antarctic Plateau during vivid optical displays (Tape 1994). As a matter of fact, the presence of the brilliant halos and arcs can be said to have served as a tracer for the hurricane cirrus during transport. In contrast, midlatitude cirrus clouds appear to be rather poor at generating brilliant optical displays other than the "common" $22^{\circ}$ halo (Sassen et al. 2002) because of the typical cirrus ice crystal morphology, which appears to be dominated by hollow and irregular particles (Sassen et al. 1994). According to the 14-year cirrus cloud research program conducted from FARS, the optical display observed on 25 September 1997 was one of most complex and brilliant. Furthermore, there is previous evidence 
that midlatitude cirrus derived from hurricanes or tropical flow can generate unusual optical displays. Although hardly conclusive, we note that the subhorizon counterpart of the parhelic circle, the subparhelic arc, along with the exceedingly rare anthelion, were photographed in October 1996 over western New York from an aircraft above the extensive cirrus shield created by the Caribbean hurricane Josephine (see Sassen et al. 1998a). The best optical display studied at FARS occurred in connection with a tropical cirrus cloud system on 16 November 1998, which produced an exceptional Parry arc (Sassen and Takano 2001).

It should be emphasized that the Nora ice crystals are unique among the data collected by the Desert Research Institute replicator device in cirrus cloud systems for their solid, pristine qualities, occasional rare shapes, and the relative lack of polycrystals or aggregates. That this is so can be appreciated by examining the extensive midlatitude cirrus replica data sample compiled at the web site, http://www.dri.edu/Projects/replica.

This information leads us to speculate that the aqueous phase chemistry associated with ice nucleation and growth may be of paramount importance to subsequent ice particle morphology in cirrus clouds. The consequences are of significance not only to halo/arc formation, but also to the basic manner in which solar radiation is scattered by ice clouds. With the exception of the homogeneous freezing of pure water drops, which does not in reality apply to upper tropospheric conditions, we are confronted with comprehending the growth of ice crystals from variously contaminated aqueous solutions. In the case of nucleation from "mildly" supercooled cloud droplets (i.e., from droplets that freeze essentially at water saturation, or at $>\sim-38^{\circ} \mathrm{C}$ ), the contamination from even extremely diluted inorganic salt solutions has been shown to have a significant impact on ice crystal morphology (Finnegan and Pitter 1997). Studies indicate that such conditions produce liquid or liquidlike layers on the growing ice surfaces, which generate charge separations depending on the nature of the contaminant (Workman and Reynolds 1950). 
For example, under the same conditions alkali salts confer an opposite charge polarity in the ionic sea-salt solution layer as compared to ammonium salt solutions. In contrast, essentially nothing is known of the situation applicable to cirrus ice crystal growth in the homogeneous freezingdominated regime. It is precisely the impacts of the haze particle freezing process in cold, concentrated solution droplets (in the form of haze particles undergoing the Köhler swelling process), that is of major consequence for improving our comprehension of basic cirrus cloud properties.

Improving this knowledge could lead to the introduction in large-scale models of a geographical/seasonal dependence of cirrus cloud radiative properties, depending on, for example, the influence of oceanic deep convective activity. It may be possible to break the problem down into a limited number of categories that depend on the $\mathrm{CCN}$ source/composition. Based on laboratory and recent cirrus research, we can now identify at least the following distinct cirrus cloud ice nucleation/growth processes that are dominated by:

i. Homogeneous freezing of aqueous sulfuric acid droplets in tropopause-topped cirrus, or along tropopause folds, perhaps resulting in acid coatings of the ice surfaces and leading to corona formation in cirrus (Sassen et al. 1995, 1998b).

ii. Homogeneous freezing of sulfate of ammonia droplets, probably responsible for the normal mode of midlatitude cirrus ice crystal production (Sassen and Dodd 1988; Heymsfield and Sabin 1989; Tabazadeh and Toon 1998).

iii. Homogeneous freezing of sea salt solution droplets, as suggested here on the basis of unusual halo/arc production (see also Sassen and Takano 2000).

iv. Heterogeneous freezing via biogenic and other IN of solution droplets through the condensation-freezing process (DeMott et al. 1998), but also dependent on the aqueous phase chemistry (Finnegan and Pitter 1997). 
v. Dry or wet deposition on special mineral particles such as desert dusts that have been shown to be effective IN (Isono et al. 1959; Schaller and Fukuta 1979; Sassen 2002b).

Each of these ice nucleation mechanisms has the potential for affecting cirrus cloud composition through differences in particle shape, and likely also on the nucleation rate, which controls particle concentration and the subsequent crystal sedimentation rate. Now that the global nature of cirrus clouds is coming under increased scrutiny, comprehending the nucleationdependent differences in cirrus cloud microphysical and radiative properties may allow us to improve our radiative parameterizations to the benefit of climate research.

Acknowledgments. This research has been funded by DOE grants DEFG02ER1059 and DEFG0398ER62571 from the Atmospheric Radiation Measurement program, NSF grant ATM-0119502, and NASA grant NAG56458. We thank J. M. Comstock for providing the LIRAD data analysis. 


\section{References}

Arnott, W. P., Y. Y. Dong, and J. Hallet, 1994: Role of small ice crystals in radiative properties of cirrus: A case study, FIRE II, November 22, 1991. J. Geophys. Res., 9, 1371-1381.

Brier, G. W., and D. B. Cline, 1959: Ocean water as a source of ice nuclei. Science, 130, 717-718.

Chen, Y., P. J. DeMott, S. M. Kreidenweis, D. C. Rogers, and D. E. Sherman, 2000: Ice formation by sulfate and sulfuric acid aerosol particles under upper-tropospheric conditions. J. Atmos. Sci., 57, 3752-3766.

Clarke, A. D., J. L. Varner, F. Eisle, R. L. Mauldin, D. Turner, and M. Litchy, 1998: Particle production in the remote marine atmosphere: Cloud outflow and subsidence during ACE 1. J. Geophys. Res., 103, 16397-16409.

Comstock, J. M., and K. Sassen, 2001: Retrieval of cirrus cloud radiative and backscattering properties using combined lidar and infrared radiometer (LIRAD) measurements. J. Ocean. Atmos. Tech., 18, 1658-1673.

DeMott, P. J., D. C. Rogers, S. M. Kreidenweis, and Y. Chen, C. H. Twohy, D. Baumgardner, A. J. Heymsfield, and K. R. Chan, 1998: The role of heterogeneous freezing nucleation in upper tropospheric clouds: Inferences from SUCCESS. Geophys. Res. Lett., 25, 1387-1390.

Duda, D. P., P. Minnis, and L. Nguyen, 2001: Estimates of cloud radiative forcing in contrail clusters using GOES imagery. J. Geophys. Res., 106, 4927-4937.

Finnegan, W. G., and R. C. Pitter, 1997: Ion-induced charge separations in growing single ice crystals: Effects on growth and interaction processes. J. Colloid Interface Sci., 189, 322-327

Fu, Q., 1996: An Accurate parameterization of the solar radiative properties of cirrus clouds for climate models. J. Climate, 9, 2058-2082.

Ghan, S. J., G. Guzman, and H. Abdul-Razzak, 1998: Competition between sea salt and sulfate particles as cloud condensation nuclei. J. Atmos. Sci., 55, 3340-3347. 
Goldsmith, J. E. M., F. H. Blair, S. E. Bisson, and D. D. Turner, 1998: Turn-key Raman lidar for profiling atmospheric water vapor, clouds, and aerosols. Appl. Opt., 37, 4979-4990.

Heymsfield, A. J., and R. M. Sabin, 1989: Cirrus crystal nucleation by homogeneous freezing of solution droplets. J. Atmos. Sci., 46, 2252-2264.

Isono, K., M. Komabayasi, and A. Ono, 1959: The nature and origin of ice nuclei in the atmosphere. J. Meteor. Soc. Japan, 37, 211-233.

Kalnay, E., and coauthors, 1996: The NCEP/NCAR 40-year reanalysis project. Bull. Amer. Meteoro. Soc., 77, 437-471.

Lin, R.F., D. O'C. Starr, P. J. DeMott, R. Cotton, K. Sassen, E. Jensen, B. Karcher, and X. Jiu, 2002: Cirrus parcel model comparison project phase I: The critical components to simulate cirrus initiation explicitly. J. Atmos. Sci., 59 (in press).

Monahan, E. C., C. W. Fairall, K. L. Davidson, and P. J. Boyle, 1983: Observed inter-relations between $10 \mathrm{~m}$ winds, ocean whitecaps and marine aerosols. Quart. J. R. Met. Soc., 109, 379-392.

Moran, K. P., B. E. Martner, M. J. Post, R. A. Kropfli, D. C. Welsh, and K. B. Widener, 1998: An unattended cloud-profiling radar for use in climate research. Bull. Amer. Meteor. Soc., 79, 443-455.

O'Dowd, C. D., and M. H. Smith, 1993: Physiochemical properties of aerosols over the northeast Atlantic: Evidence for wind speed related submicron sea-salt aerosol production. J. Geophys. Res., 98, 1137-1149.

Pruppacher, H. R., and J. D. Klett, 1997: Microphysics of Clouds and Precipitation, 2nd Ed., Kluwer, 954 pp.

Sassen, K., 1980: Remote sensing of planar ice crystal fall attitudes. J. Meteor. Soc. Japan, 58, 422-429.

Sassen, K., 1999: Cirrus clouds and haloes: A closer look. Optics E Photonics News, 10, 39-42.

Sassen, K., 2002a: Cirrus Clouds: A Modern Perspective, in Cirrus, D. Lynch et al., Eds. Oxford University Press, 11-40. 
Sassen, K., 2002b: Indirect climate forcing over the western US from Asian dust storms. Geophys. Res. Lett., 29 (in press).

Sassen, K., and G. C. Dodd, 1988: Homogeneous nucleation rate for highly supercooled cirrus cloud droplets. J. Atmos. Sci., 45, 1357-1369.

Sassen, K., N. C. Knight, Y. Takano, and A. J. Heymsfield, 1994: Effects of ice crystal structure on halo formation: Cirrus cloud experimental and raytracing modeling studies. Appl. Opt., 33, 4590-4601.

Sassen, K., D. O'C. Starr, G. G. Mace, M. R. Poellot, S. H. Melfi, W. L. Eberhard, J. D. Spinhirne, E. W. Eloranta, D. E. Hagen, and J. Hallett, 1995: The 5-6 December 1991 FIRE IFO II jet stream cirrus case study: Possible influences of volcanic aerosols. J. Atmos. Sci., 52, 97-123.

Sassen, K., W. P. Arnott, J. M. Barnett, and S. Aulenbach, 1998a: Can cirrus clouds produce glories? Appl. Opt., 37, 1427-1433.

Sassen, K., G. G. Mace, J. Hallett, and M. R. Poellot, 1998b: Corona-producing ice clouds: A case study of a cold cirrus layer. Appl. Opt., 37, 1477-1585.

Sassen, K., and Y. Takano, 2000: Parry arc: A polarization lidar, ray tracing, and aircraft case study. Appl. Opt., 39, 6738-6745.

Sassen, K., and J. R. Campbell, 2001: A midlatitude cirrus cloud climatology from the Facility for Atmospheric Remote Sensing: I. Macrophysical and synoptic properties. J. Atmos. Sci., 58, 481-496.

Sassen, K., and S. Benson, 2001: A midlatitude cirrus cloud climatology from the Facility for Atmospheric Remote Sensing: II. Microphysical properties derived from lidar depolarization. J. Atmos. Sci., 58, 21032112.

Sassen, K., and J. M. Comstock, 2001: A midlatitude cirrus cloud climatology from the Facility for Atmospheric Remote Sensing: III. Radiative properties. J. Atmos. Sci., 58, 2113-2127.

Sassen, K., J. M. Comstock, Z. Wang, and G. G. Mace, 2001: Cloud and aerosol research capabilities at FARS: The Facility for Atmospheric Remote Sensing. Bull. Amer. Meteor. Soc., 82, 1119-1138. 
Sassen, K., J. Zhu, and S. Benson, 2002: A midlatitude cirrus cloud climatology from the Facility for Atmospheric Remote Sensing: IV. Optical displays. Appl. Opt., (submitted).

Saxena, V. K., 1983: Evidence of the biogenic nuclei involvement in Antarctic coastal clouds. J. Phys. Chem., 87, 4130-4134.

Schaller, R. C., and N. Fukuta, 1979: Ice nucleation by aerosol particles: Experimental studies using a wedge-shaped ice thermal diffusion chamber. J. Atmos. Sci., 36, 1788-1802.

Schnell, R. C., and G. Vali, 1976: Biogenic ice nuclei. I: Terrestrial and marine sources. J Atmos. Sci., 33, 1554-1564.

Starr, D. O'C., and D. P. Wylie, 1990: The 27-23 October 1986 FIRE cirrus case study: Meteorology and clouds. Mon. Wea. Rev., 118, 2259-2287.

Stokes, G. M., and S .E. Schwartz, 1994: The Atmospheric Radiation Measurement (ARM) program: Programmatic background and design of the cloud and radiation testbed. Bull. Amer. Meteor. Soc., 75, 1201-1221.

Tabazadeh, A., and O. B. Toon, 1998: The role of ammoniated aerosols in cirrus cloud nucleation. Geophys. Res. Lett., 25, 1379-1382.

Tape, W., 1994: Atmospheric Halos. Antarctic Research Series 64., Amer. Geophys. Union, Washington, D. C.

Tränkle, E., and R. G. Greenler, 1987: Multiple scattering effects in halo phenomena. J. Opt. Soc. Am., A4, 591-599.

Wang, Z., and K. Sassen, 2002: Cirrus cloud microphysical property retrieval using lidar and radar measurements: I. Algorithm description and comparison with in situ data. J. Appl. Meteor., 41, 218-229.

Workman, E. J., and E. E. Reynolds, 1950: Electrical phenomena occurring during the freezing of dilute aqueous solutions and their possible relationship to thunderstorm activity. Phys. Rev., 78, 254-259. 


\section{Figure Captions}

Figure 1. Evolution of the indicated synoptic weather conditions following the decay of hurricane Nora, derived from NCEP reanalysis. Gray scales for absolute vorticity and relative humidity are inserted at bottom.

Figure 2. Sequence of 12-hourly infrared channel GOES views of the western US showing the decay of hurricane Nora and the spread of the cirrus cloud shield across the southwest on 24 September, the University of Utah FARS site on 25 September, and the Southern Great Plains CART site on 26 September 1997.

Figure 3. Time sequence of three-hourly radiosonde observations from the Southern Great Plains CART site near Lamont (LAM) Oklahoma, over the period of 2100 UTC on 25 September to 0300 UTC 27 September 1997. Plotted in the upper panels are vertical profiles of temperature (progressively offset by $10^{\circ} \mathrm{C}$ ) and potential temperature (offset by $10 \mathrm{~K}$ ). A time-height analysis of relative humidity (via standard processing but converted to with respect to ice at upper levels) is given in the lower left panel. At lower right is shown a time-height isotach wind analysis, where wind direction is indicated by constant-length barbs. The variable wind directions at low levels are associated with very light winds.

Figure 4. Expanded views of GOES infrared images over the SGP CART site (X symbol) from 1800-2130 UTC on 26 September 1997.

Figure 5. Summary of remote sensing data collected as the leading edge of the Nora cirrus cloud shield advected over FARS. From top to bottom are shown representative fish-eye photographs (note time stamps), CPL relative returned energy (based on a logarithmic gray scale), with 0000 UTC Salt Lake City sounding profiles of temperature (solid) and dew point temperature at right, and linear depolarization ratio (see color $\delta$ value key) height versus time displays.

Figure 6. Overview, from top to bottom, of PDL $0.532 \mu \mathrm{m}$ relative returned energy (based on a logarithmic gray scale) and linear depolarization 
ratios (see color $\delta$ value key), and MMCR equivalent radar reflectivity factor and Doppler vertical velocity (see color keys) displays of the cirrus remnants of Nora over the SPL CART site during the Citation aircraft mission on 26 September. Positive Doppler velocities indicate downward motions.

Figure 7. Overview of Citation aircraft data in terms of pressure-corrected flight altitude (superimposed over the PDL $\delta$-value display), aircraft distance from the CART site, and 5-s averages of 2D-C probe ice crystal number concentration $(\mathrm{N})$, average maximum dimension $\left(\mathrm{D}_{\max }\right)$, and ice water content (IWC) derived from the two methods described in the text. Figure 8.Vertical profiles of $2 \mathrm{D}-\mathrm{C}$ measured $\mathrm{N}, \mathrm{D}_{\mathrm{m}}$, and IWC obtained from 2025-2055 UTC on 26 September as the Citation performed spirals in the vicinity of the CART site. The $\otimes$ symbols provide $250-\mathrm{m}$ height averages of the data. Average in situ temperatures are shown at right.

Figure 9. Expanded view of the lidar depolarization and 5-s average in situ data, as in Fig. 7, from the indicated period showing a doubled-layered cirrus with breaking Kelvin-Helmholtz waves. The IWC data were computed using the Wang and Sassen (2002) method.

Figure 10. Detailed view of lidar relative returned energy and depolarization in the breaking Kelvin-Helmholtz waves. The lidar data were collected at $1.5-\mathrm{m}$ height and $0.1-\mathrm{s}$ time resolutions.

Figure 11. Sequence of replicator-preserved ice crystal images collected over two periods corresponding to the aircraft segment in Fig. 9. Note the 100 $\mu \mathrm{m}$ scales at top.

Figure 12. Expanded view of the lidar depolarization and in situ data, as in Fig. 9, from the indicated period as the aircraft traversed a mesoscale uncinus complex.

Figure 13. Sequence of replicator-preserved ice crystal images collected over the period corresponding to a portion of the aircraft segment in Fig. 12. 
Figure 14. Expanded view of lidar depolarization and in situ data, as in Fig. 12.

Figure 15. Sequence of replicator-preserved ice crystal images collected over the period corresponding to the aircraft segment in Fig. 14. Note that in parts $b$ and $d$ two size scales have been used in the images.

Figure 16. Selected replicator images of plate and column ice crystals showing central features resembling plankton and offer microbes ranging from a few microns up to $\sim 40 \mu \mathrm{m}$ in maximum dimension. Note the apparent algae cell at the center of the broken plate crystal at upper right, which displays features of cell morphology.

Figure 17. Composite of data derived from SGP CART data using an advanced radar/lidar algorithm of, from top to bottom, generalized effective size field, field of $\log$ IWC, vertically-integrated ice water path (IWP), visible cloud optical depth ( $\tau$, using the two methods described in the text), and infrared layer emittance $(\varepsilon)$ over the period of the aircraft mission. 
500mb Geopotential Heights (m)

24 September 1997, $12 Z$
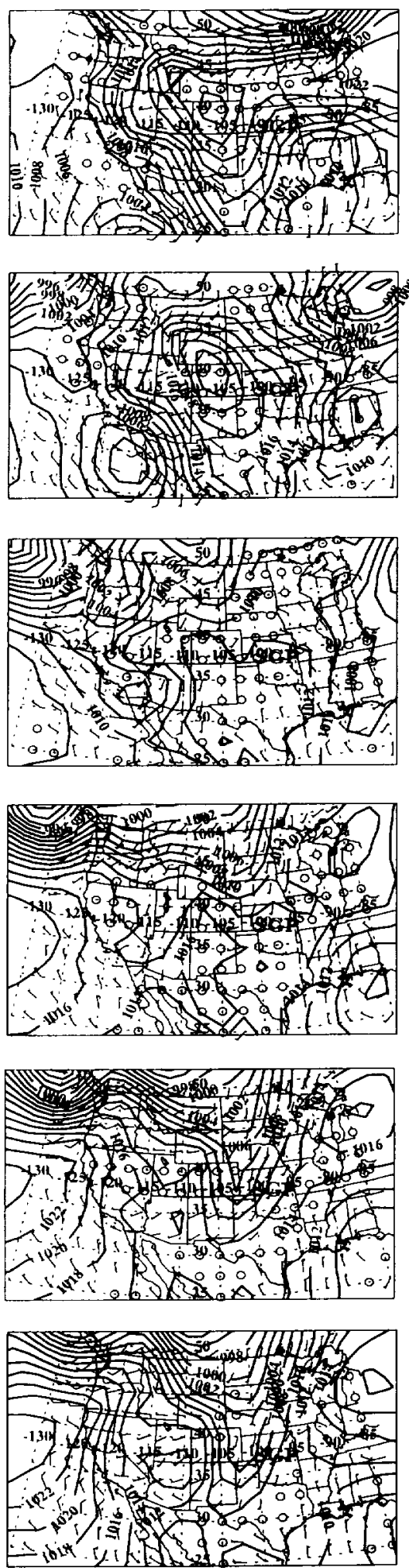

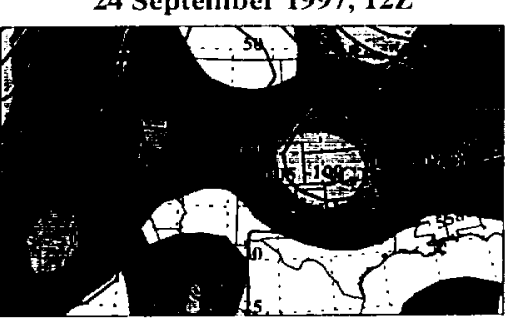

25 September 1997, $12 Z$

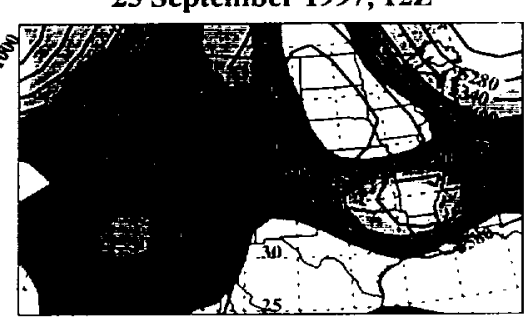

26 September 1997, 00Z

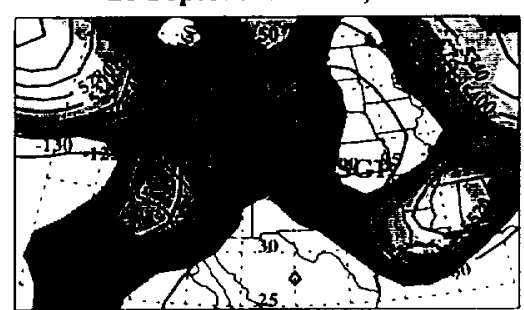

26 September 1997, $12 Z$
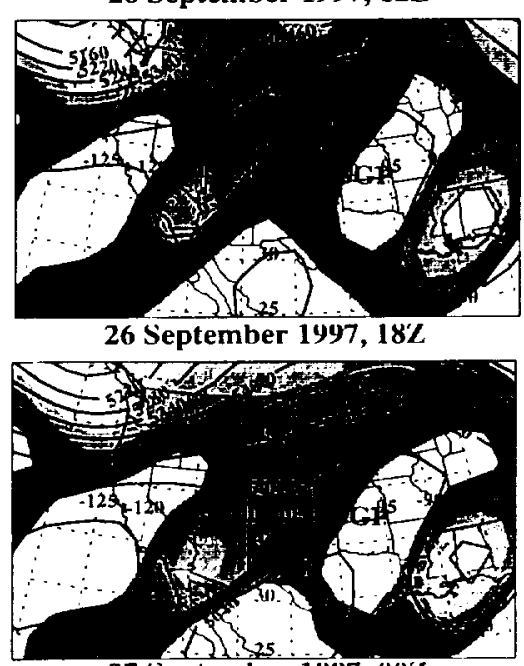

27 September $1997,00 \mathrm{~K}$

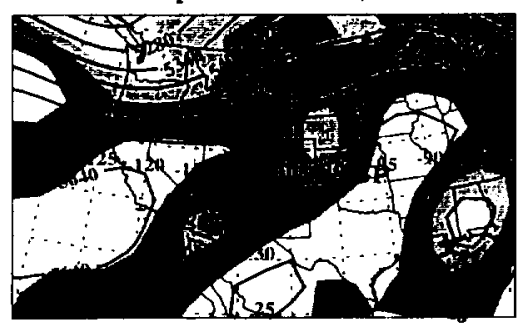

Absolute Vorticity $\left(10^{n-5 / 5}\right)$

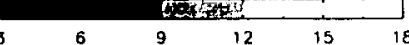

26 September 1997, 18Z
$250 \mathrm{mb}$ Vertical Velocity $(\mathrm{cm} / \mathrm{s})$
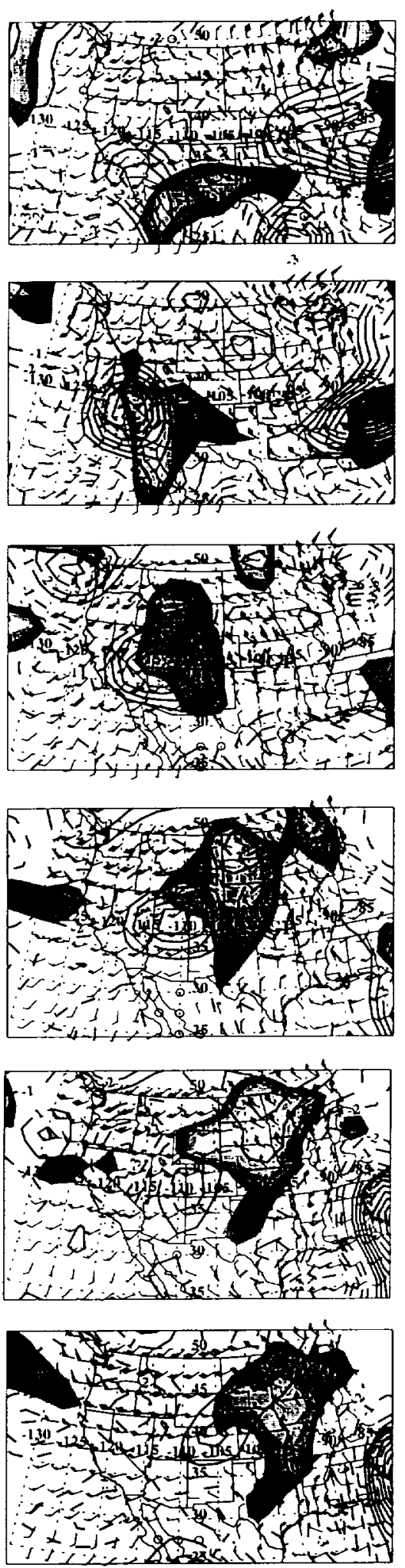

$300 \mathrm{mb}$ Relotive Humidity (\%)

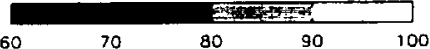




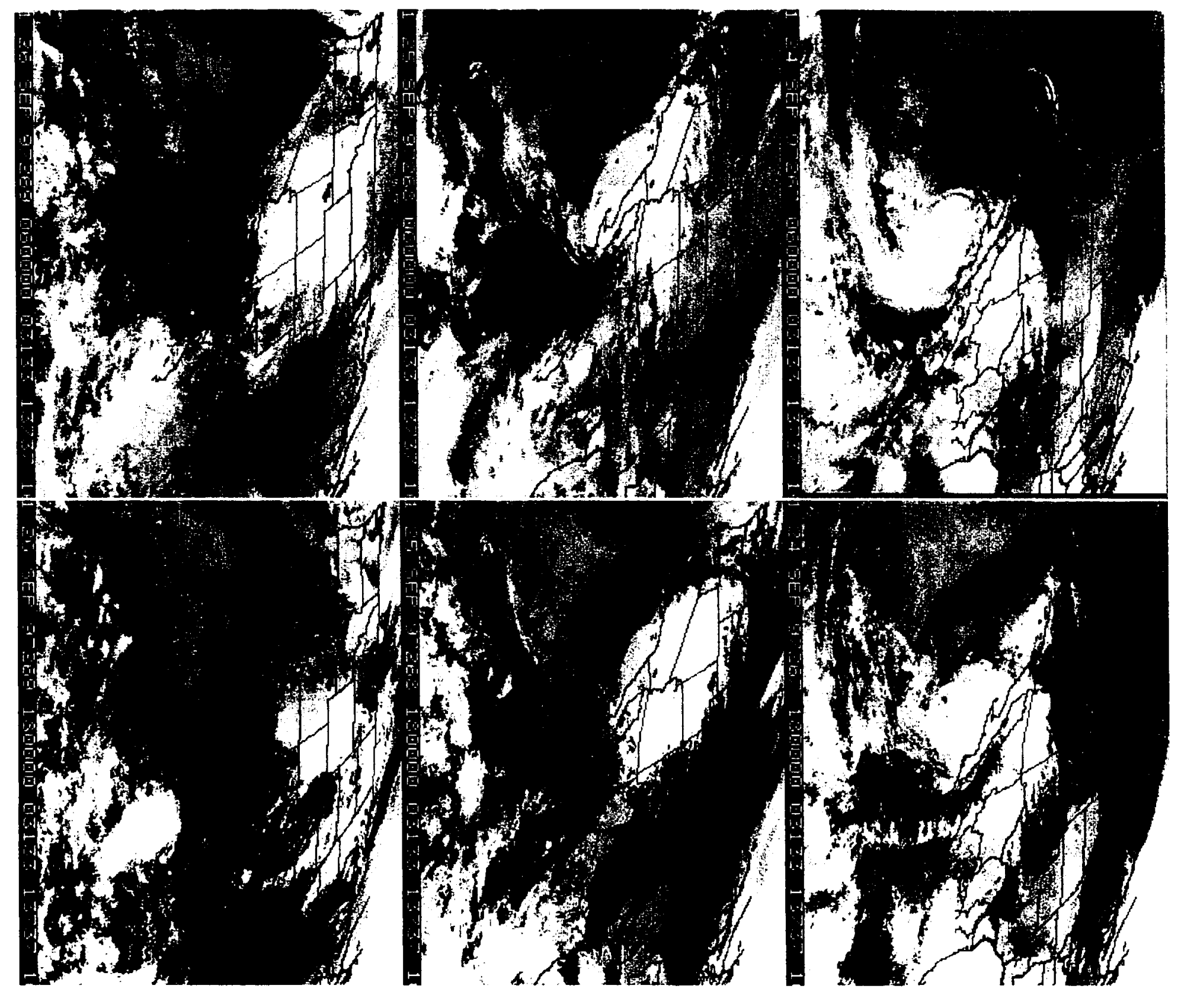


1 


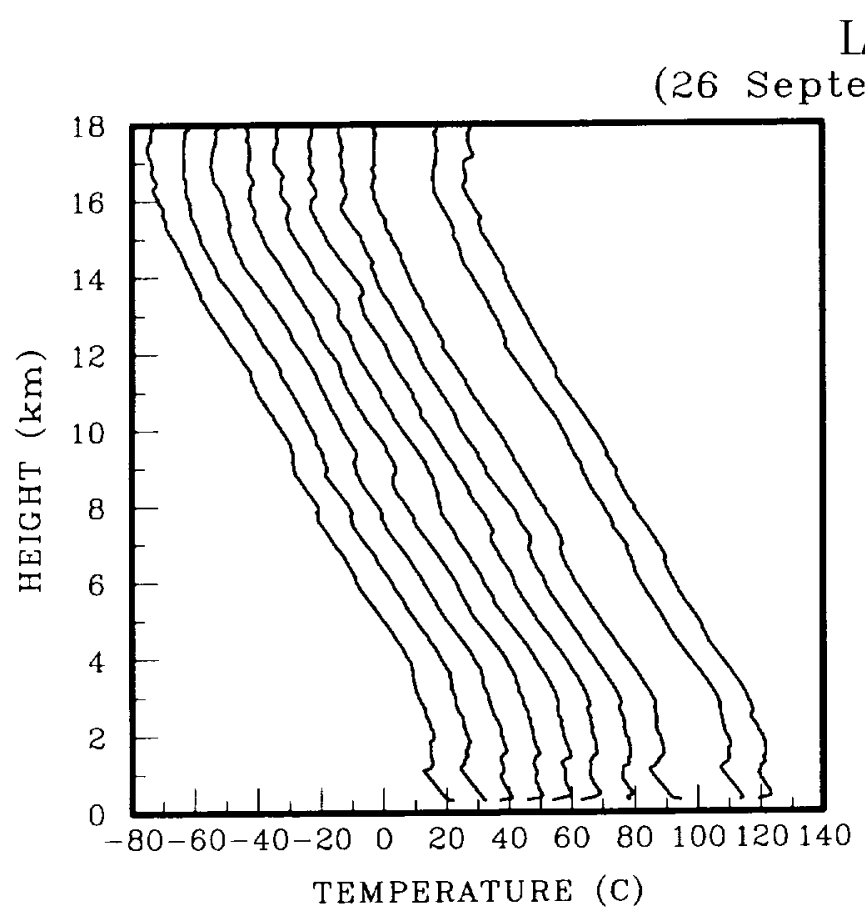

LAM

mber 1997)
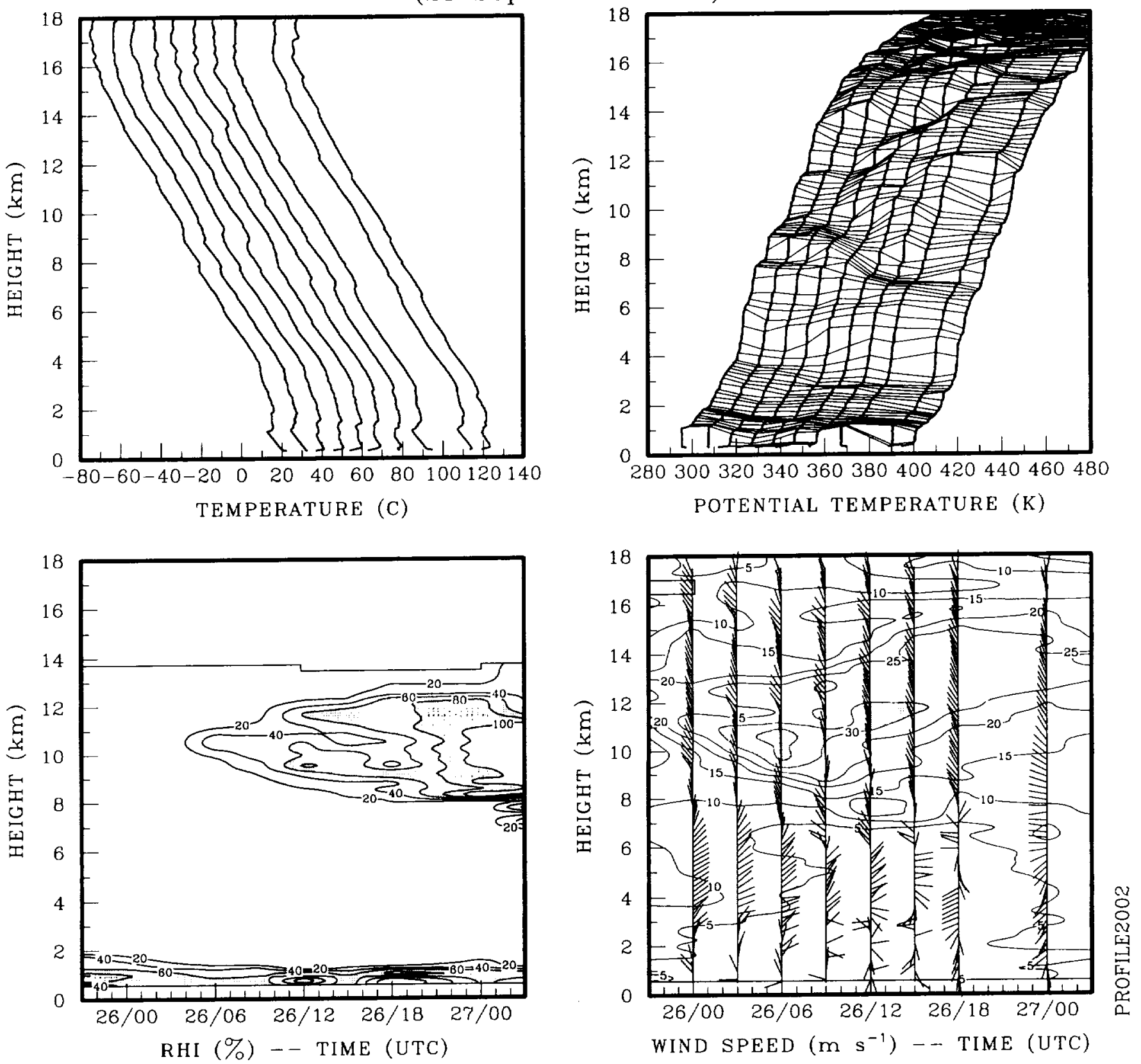


$$
1
$$




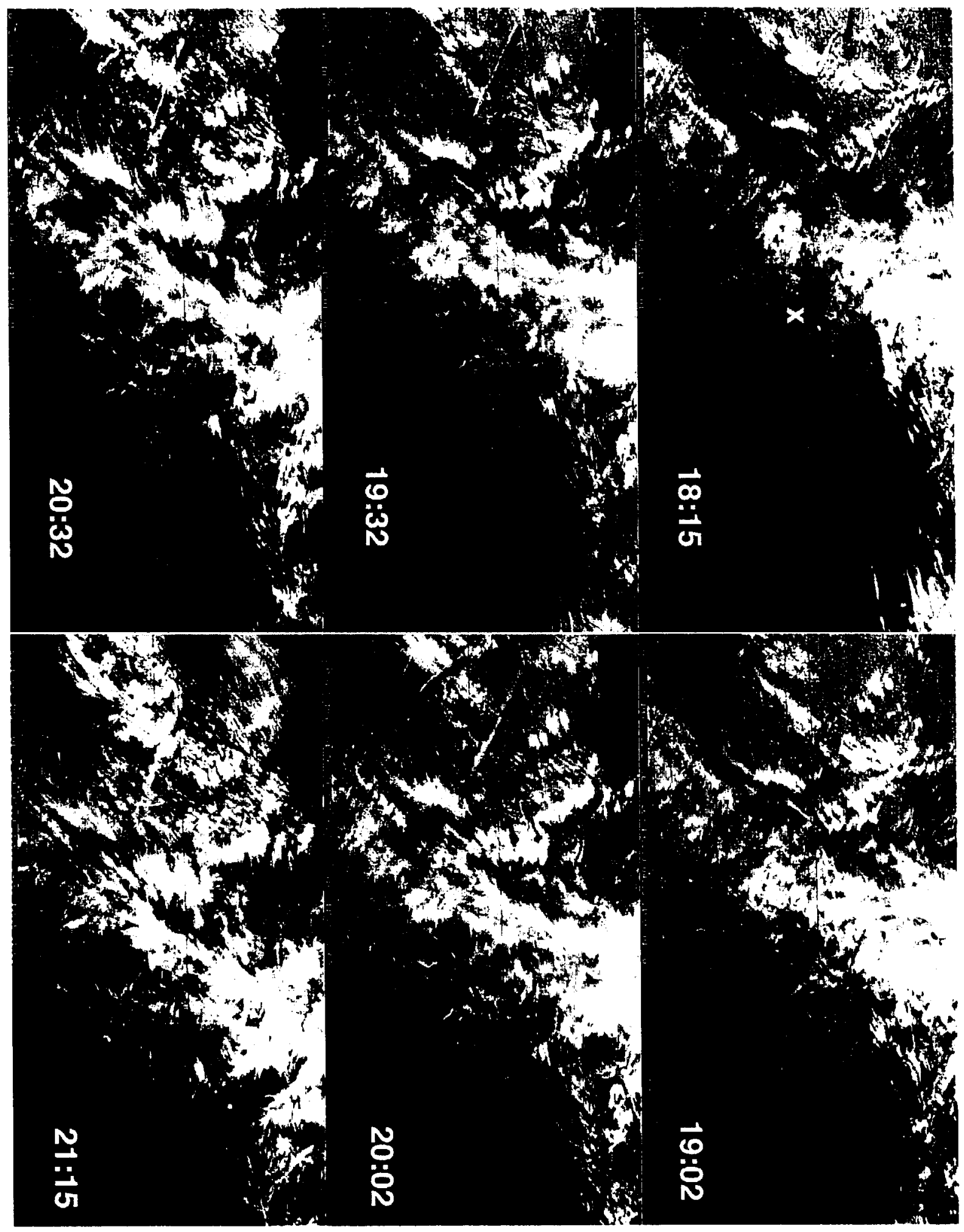


1 


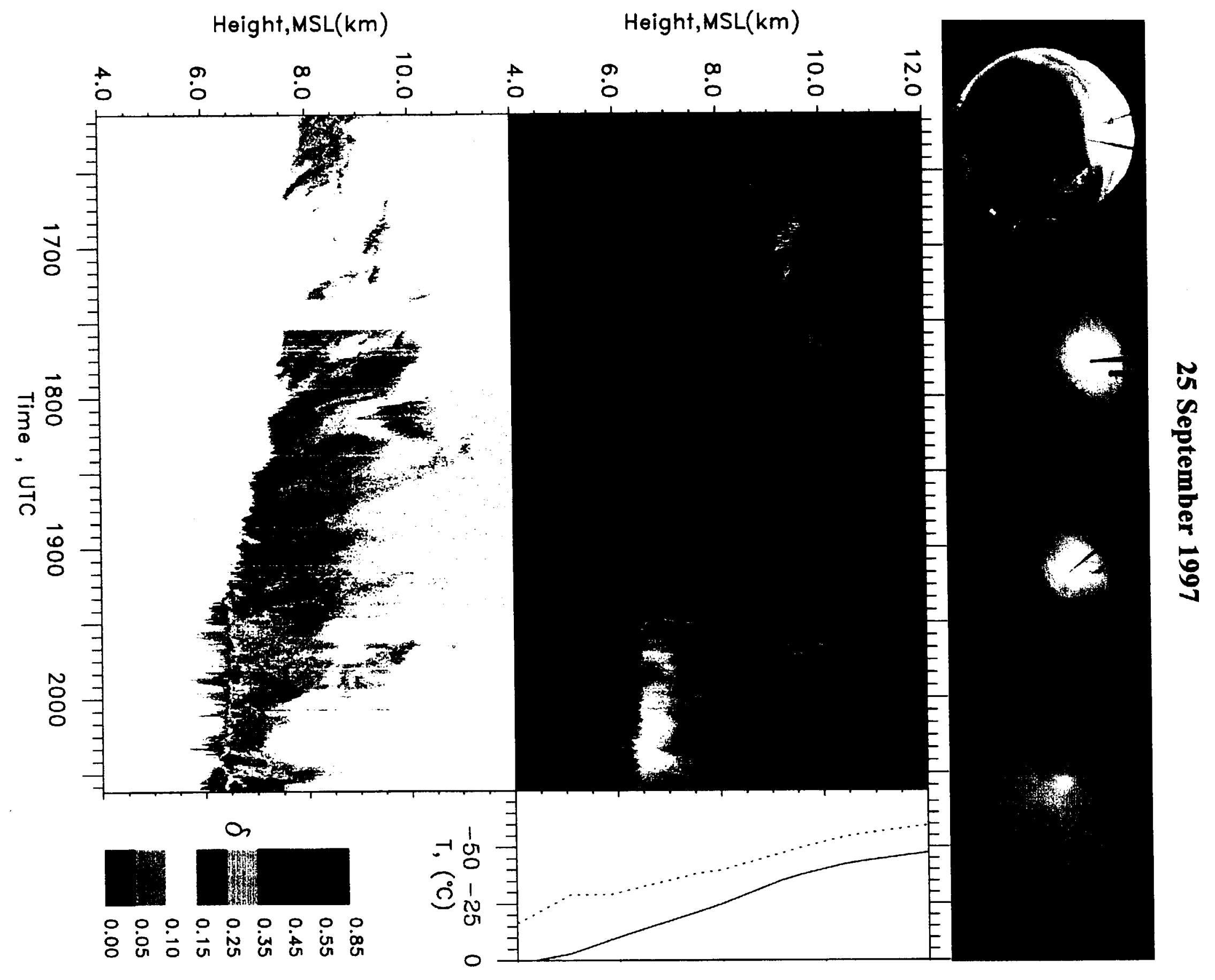




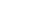
I 


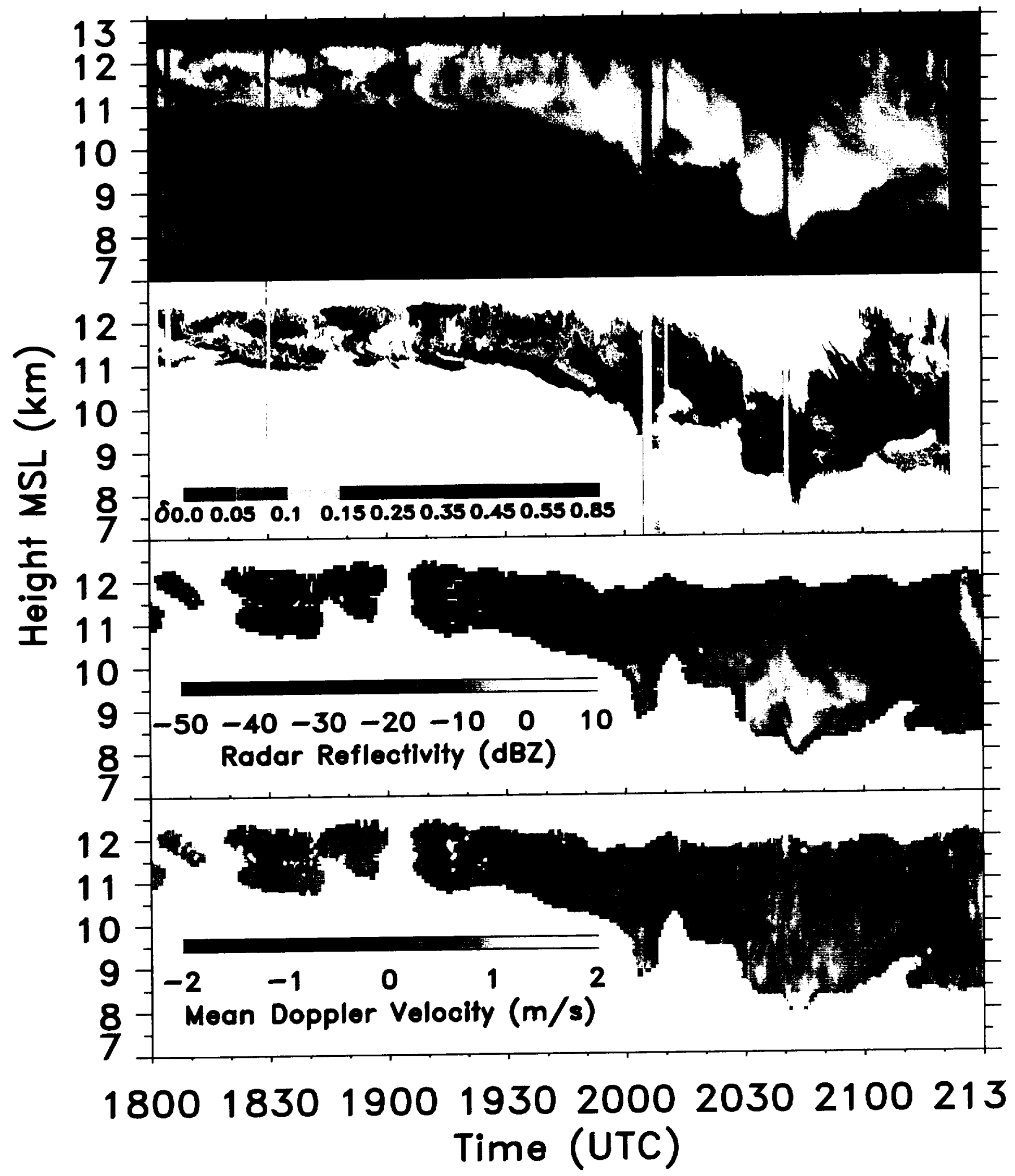

Fig. 5b 


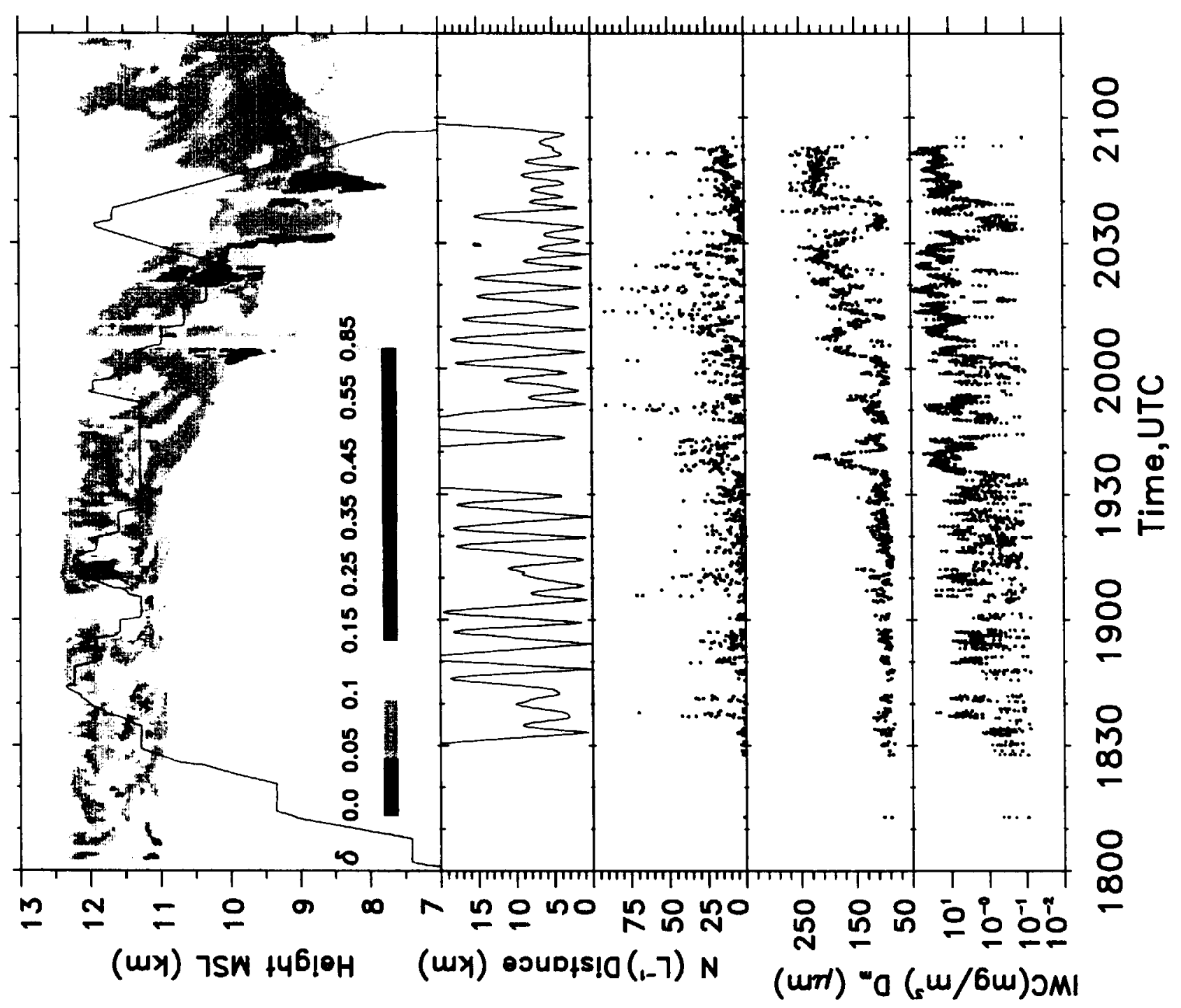


1 


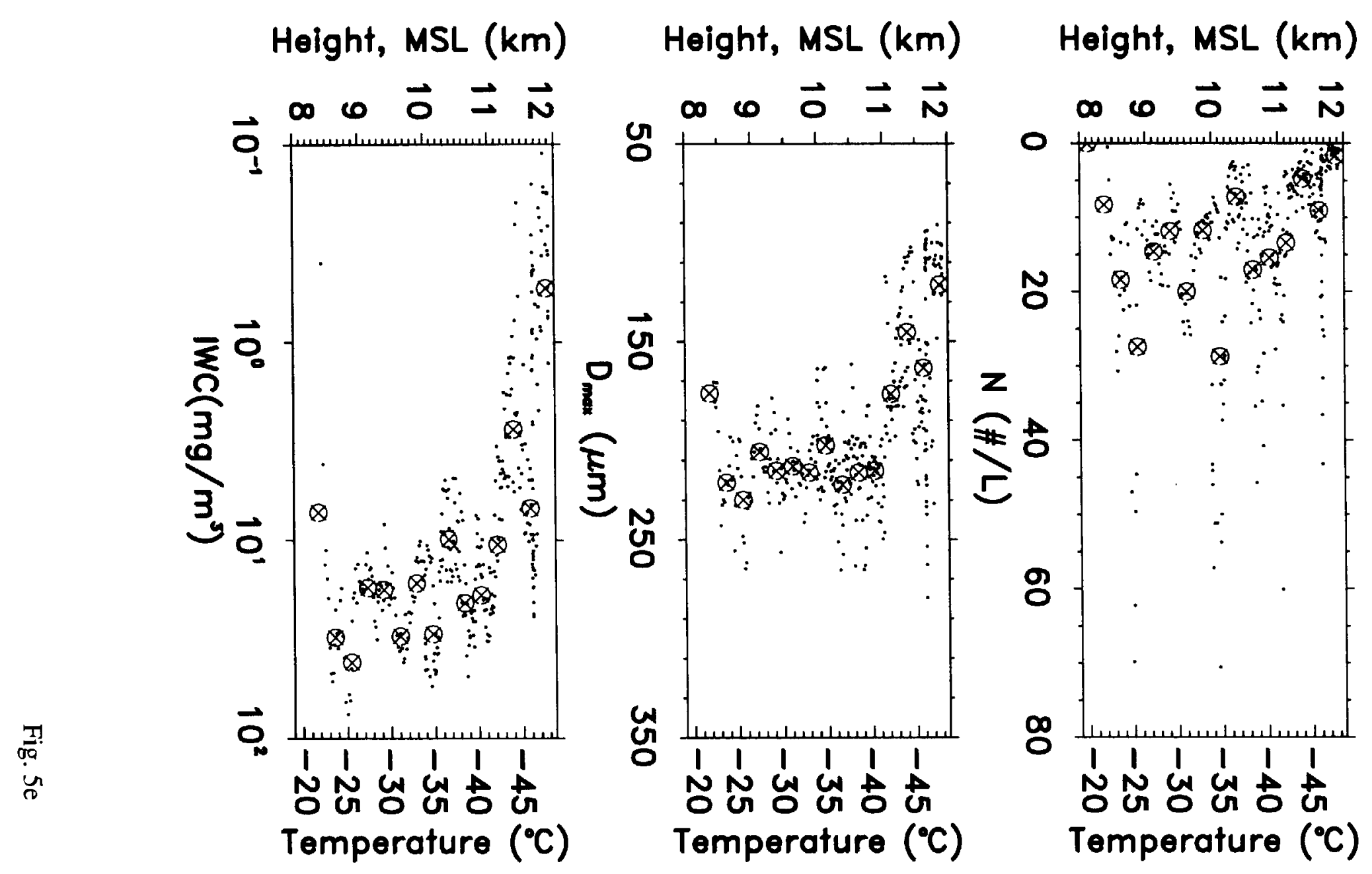




$$
1
$$




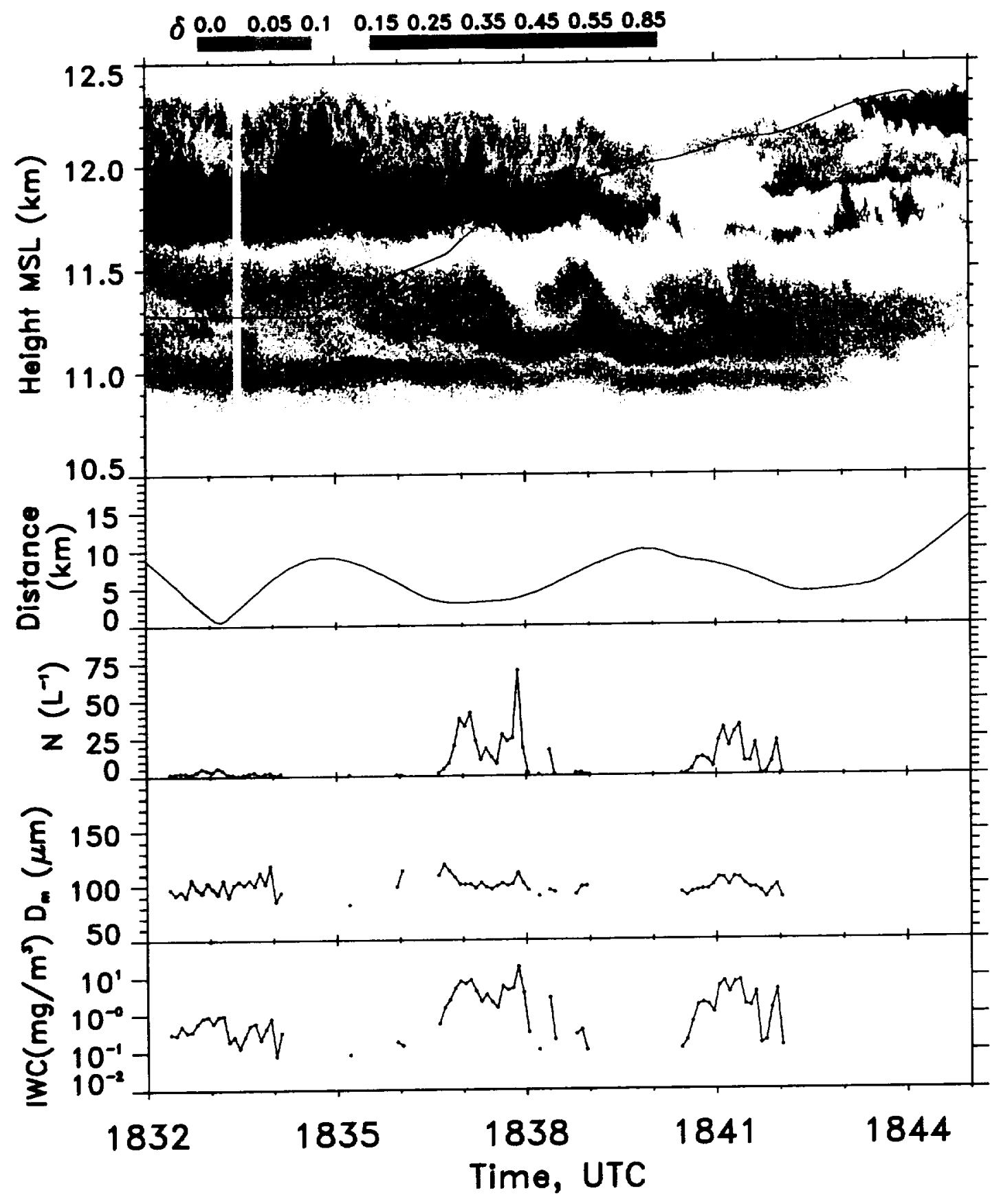

Fig. $5 f$ 
1 


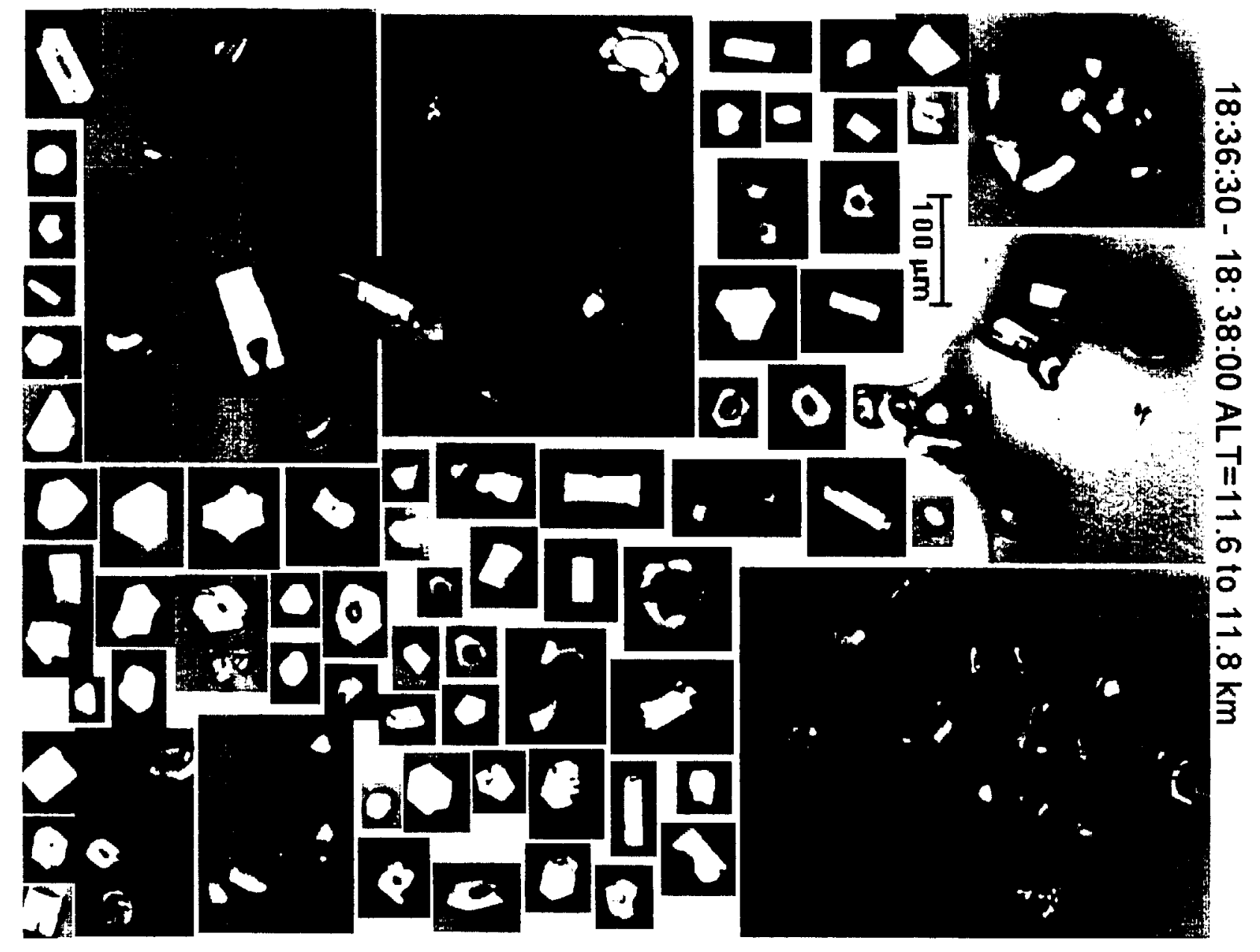


1 


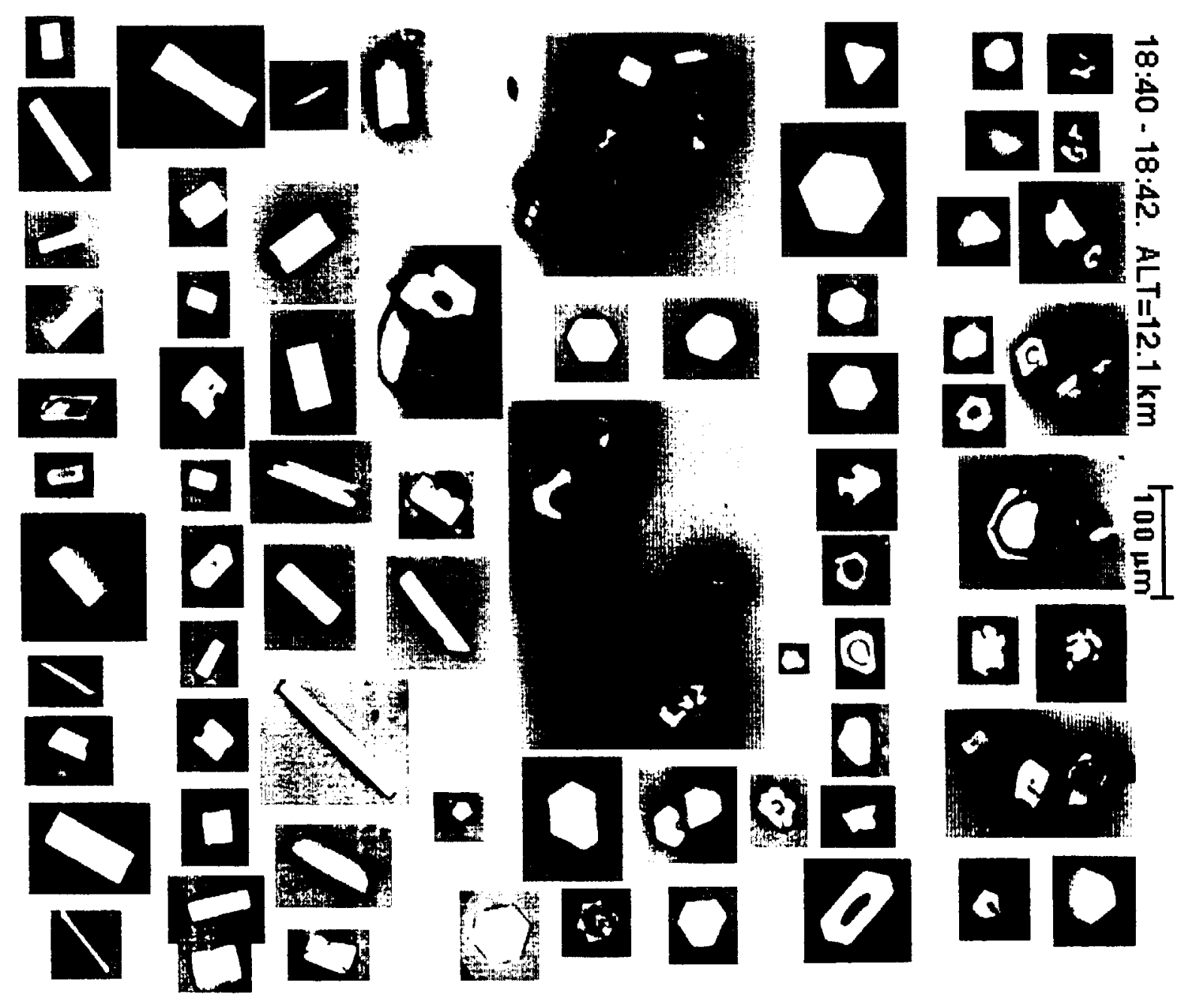


I 

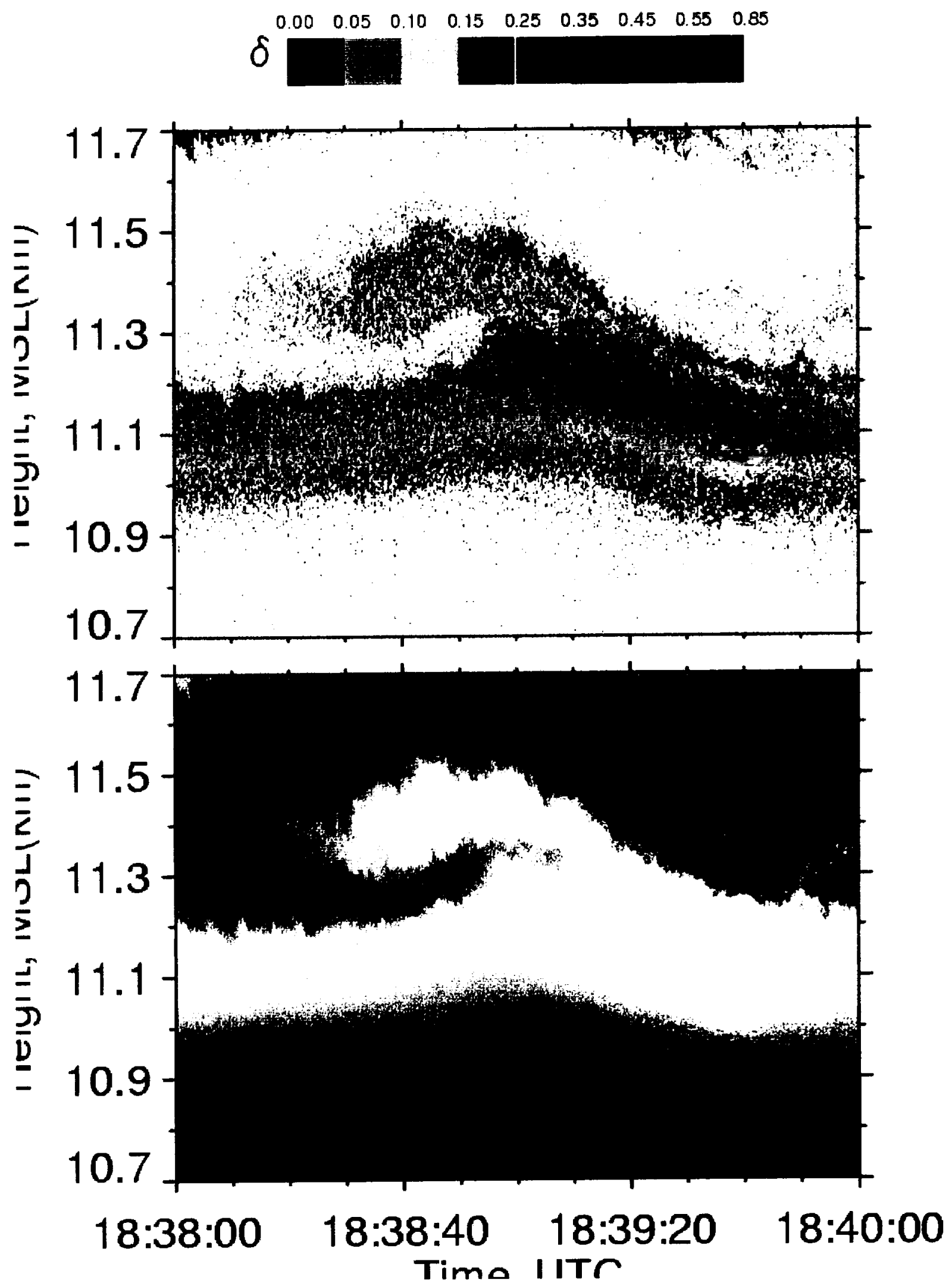


$$
1
$$




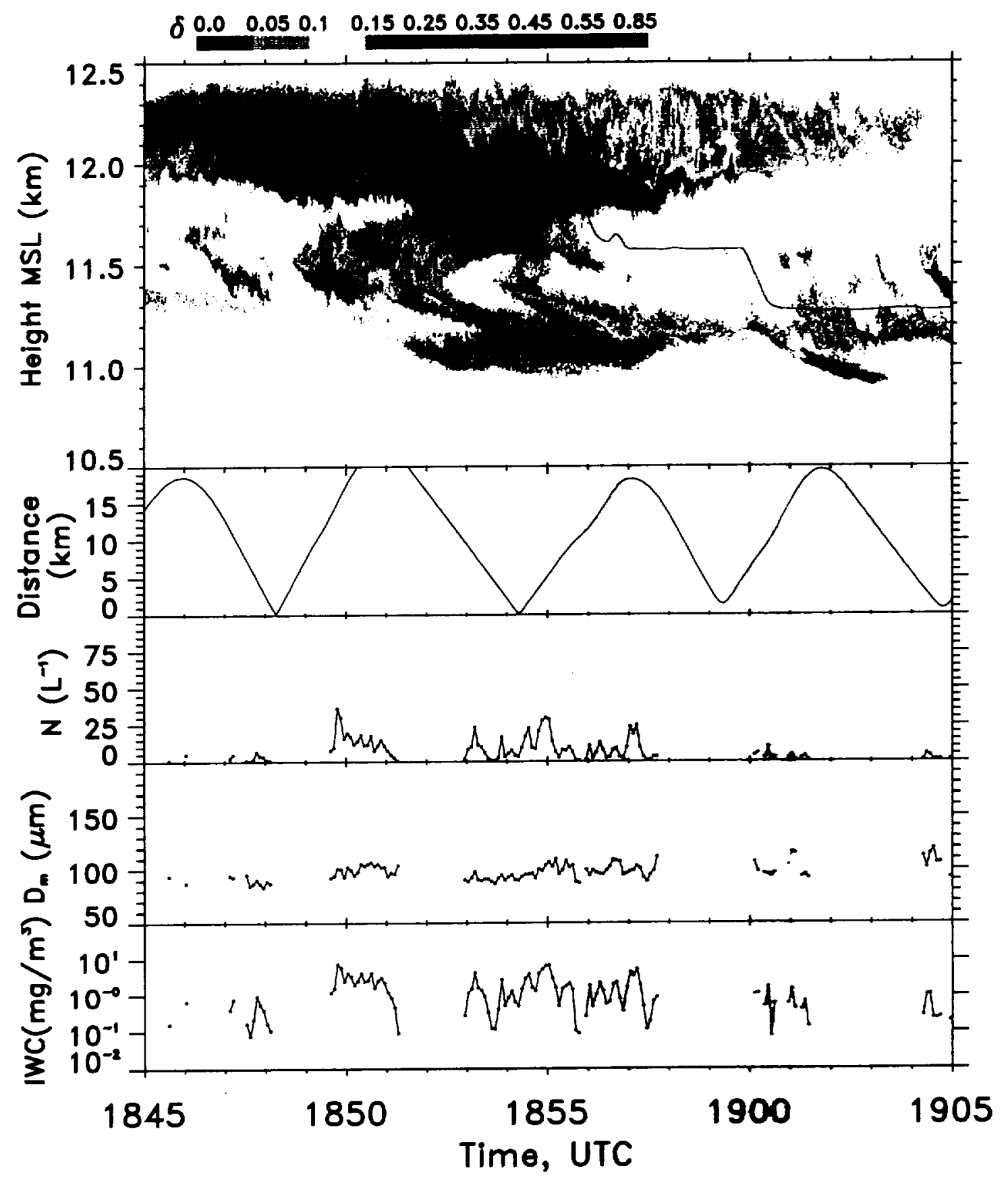

Fig. $5 \mathrm{~h}$ 
, 


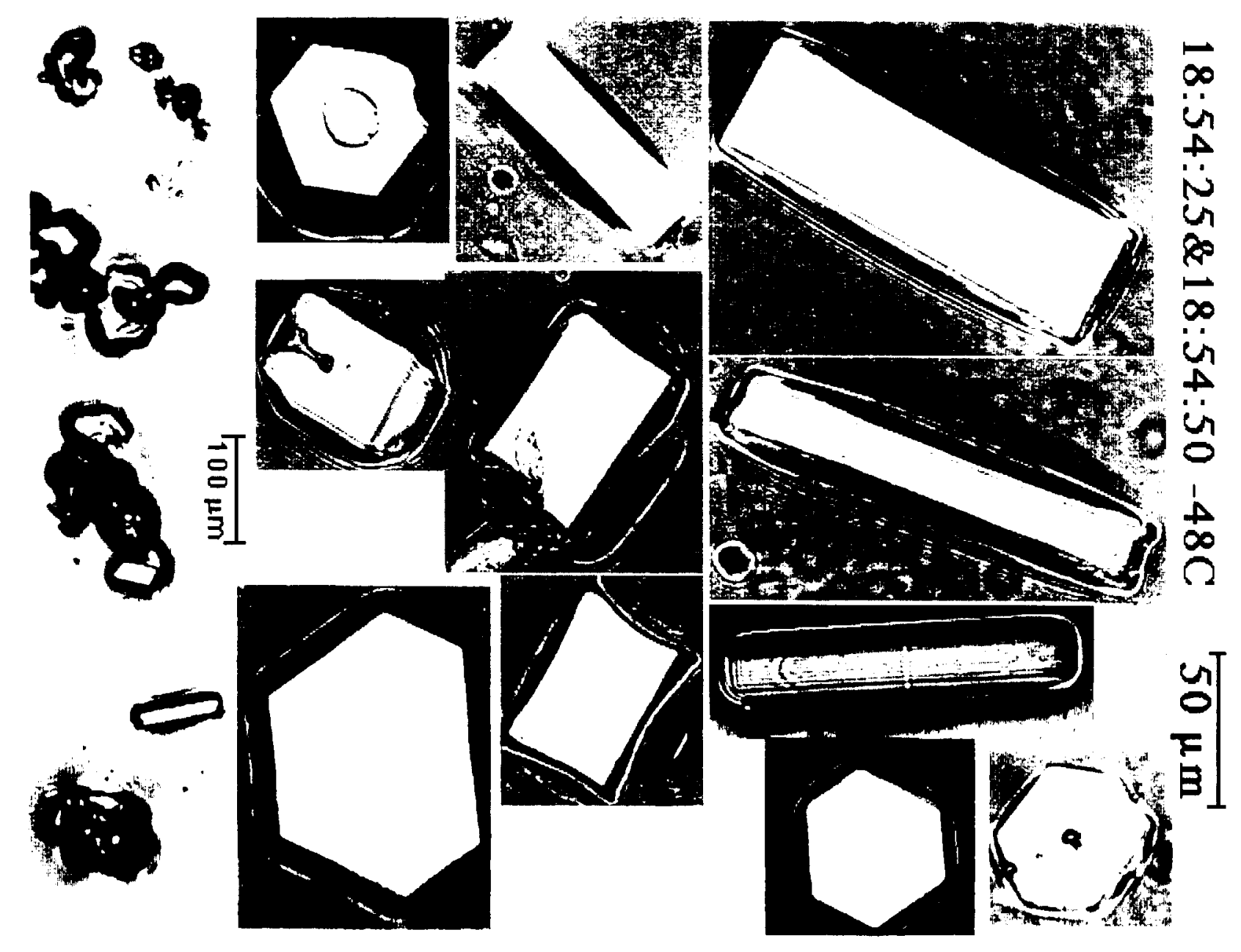


1 


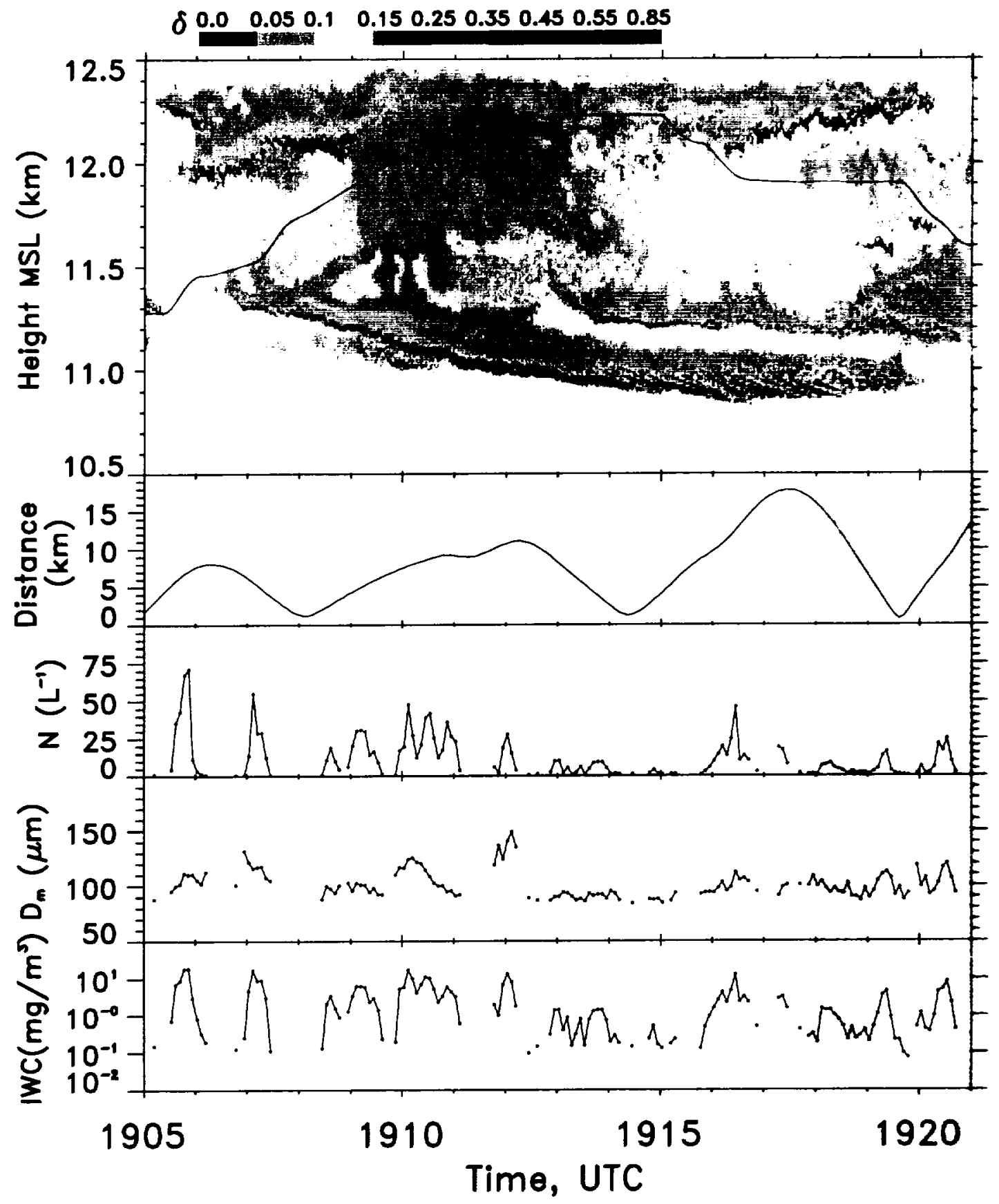


1 


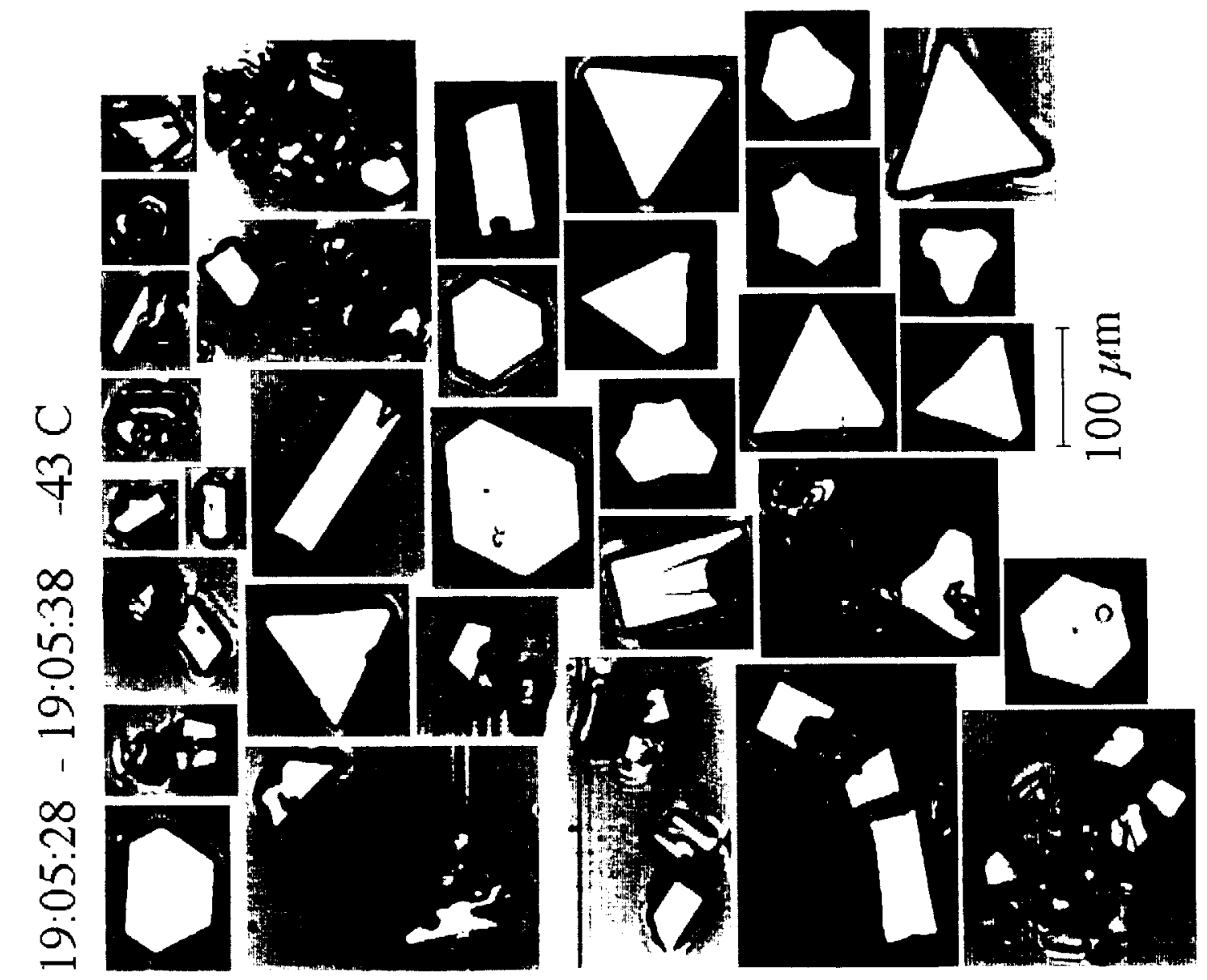


1 


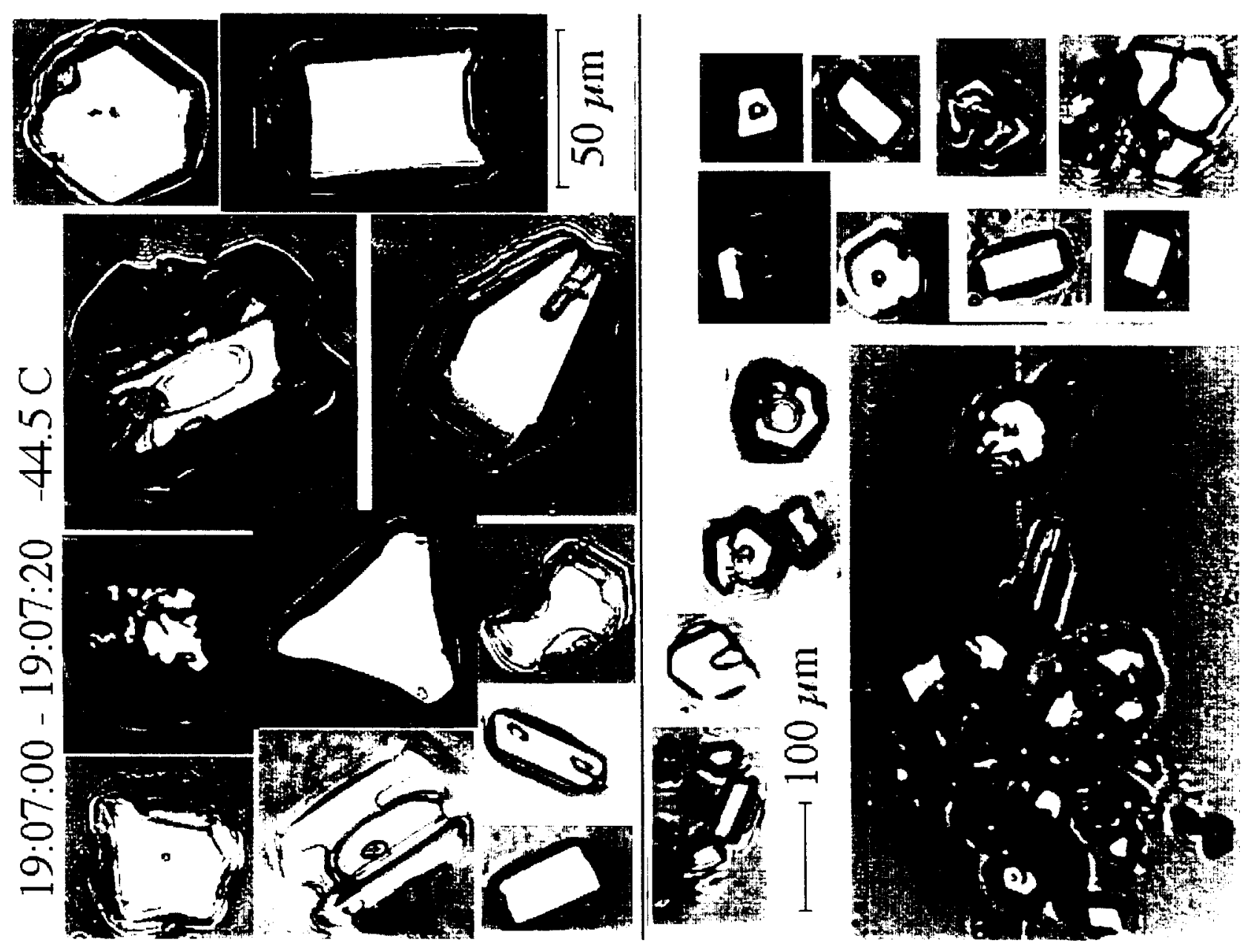


1 


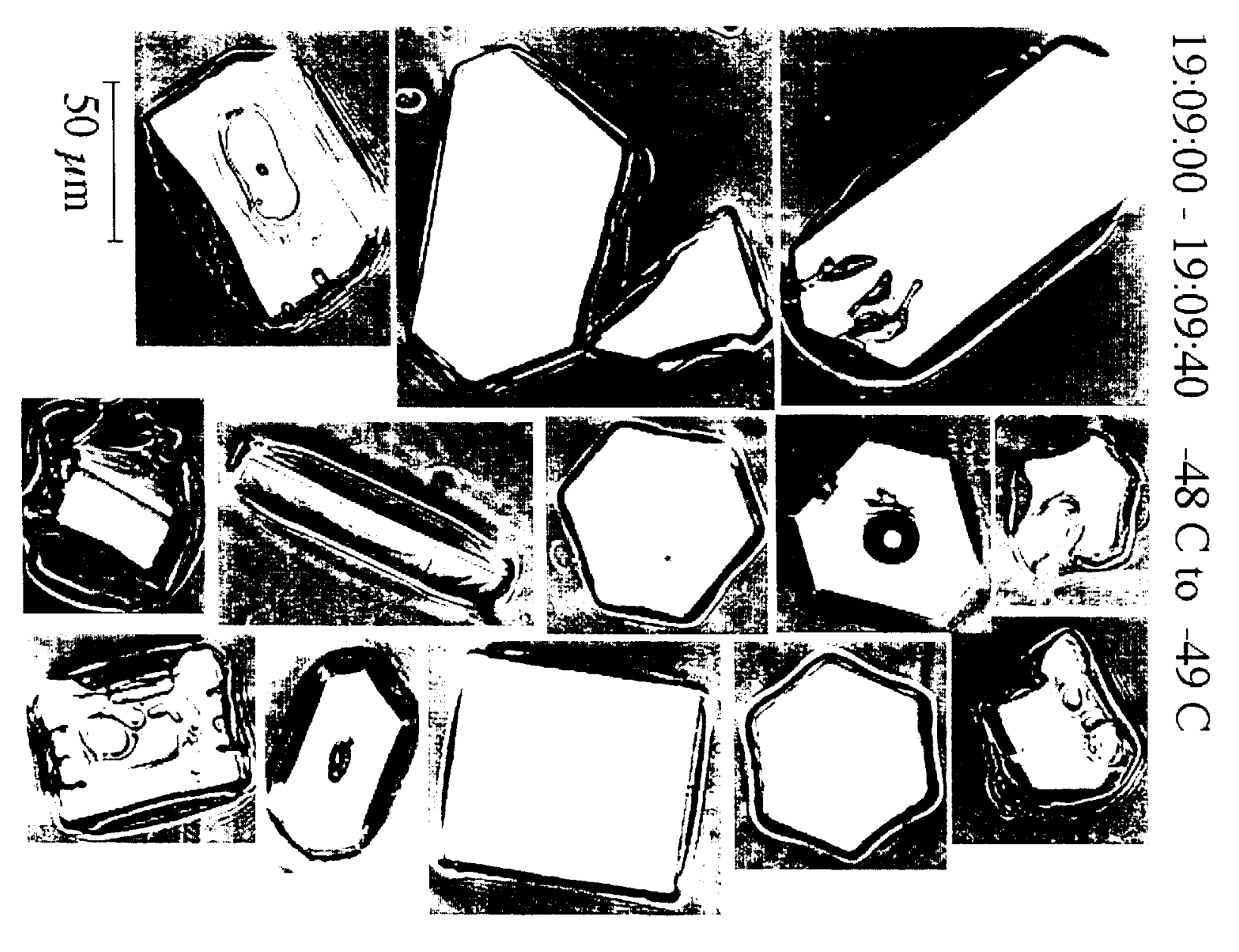




$$
1
$$




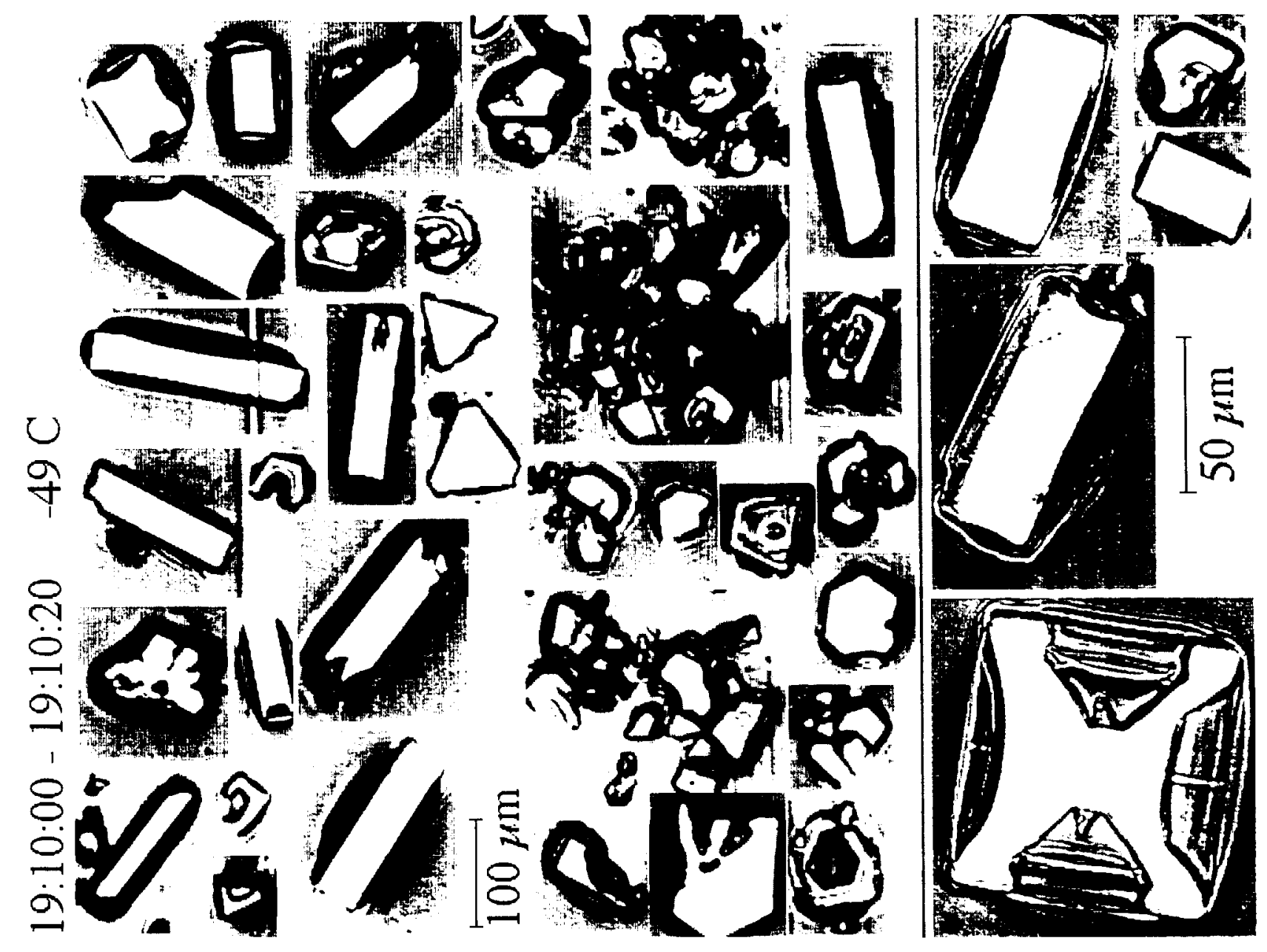




$$
1
$$




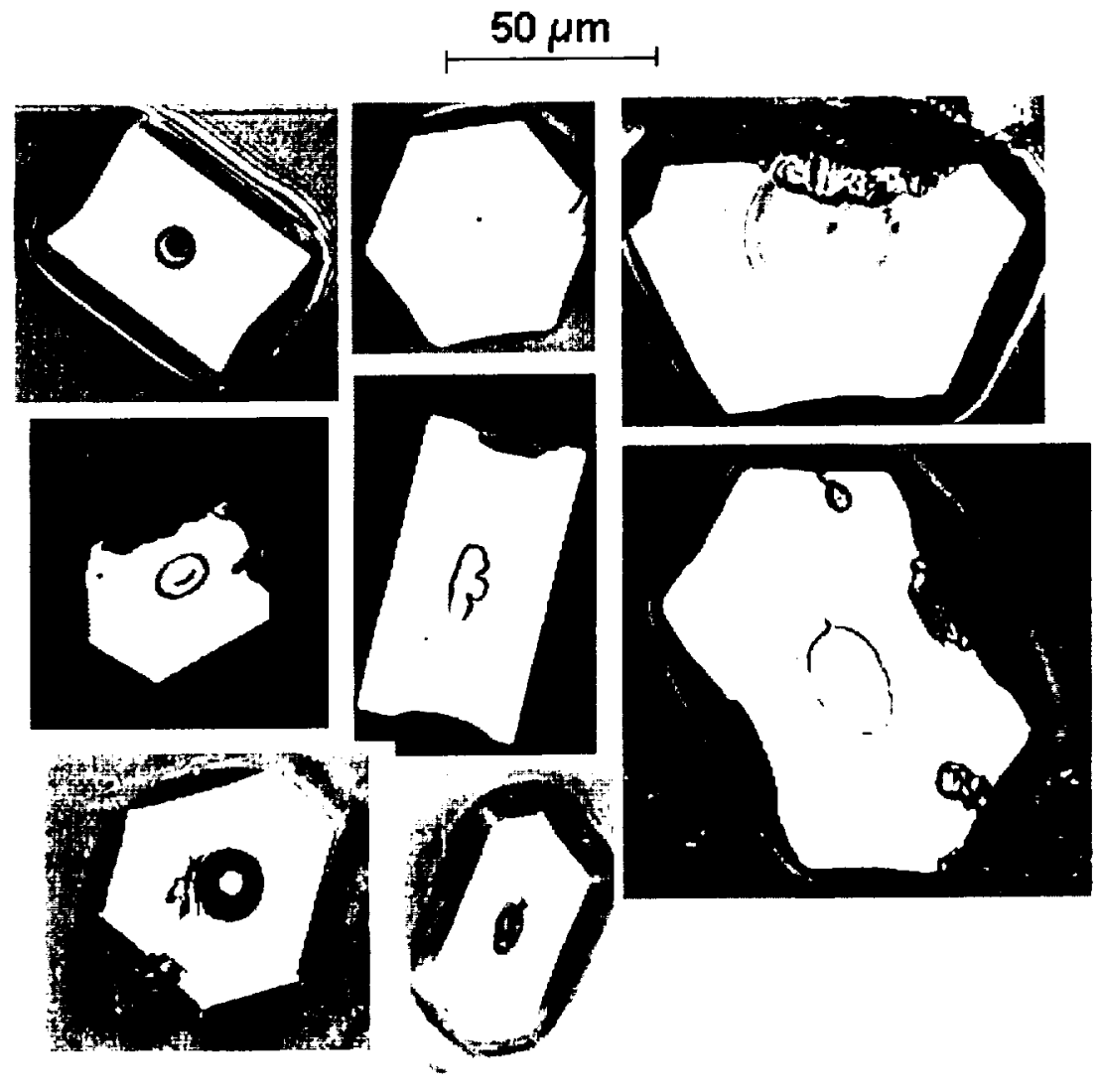




$$
1
$$




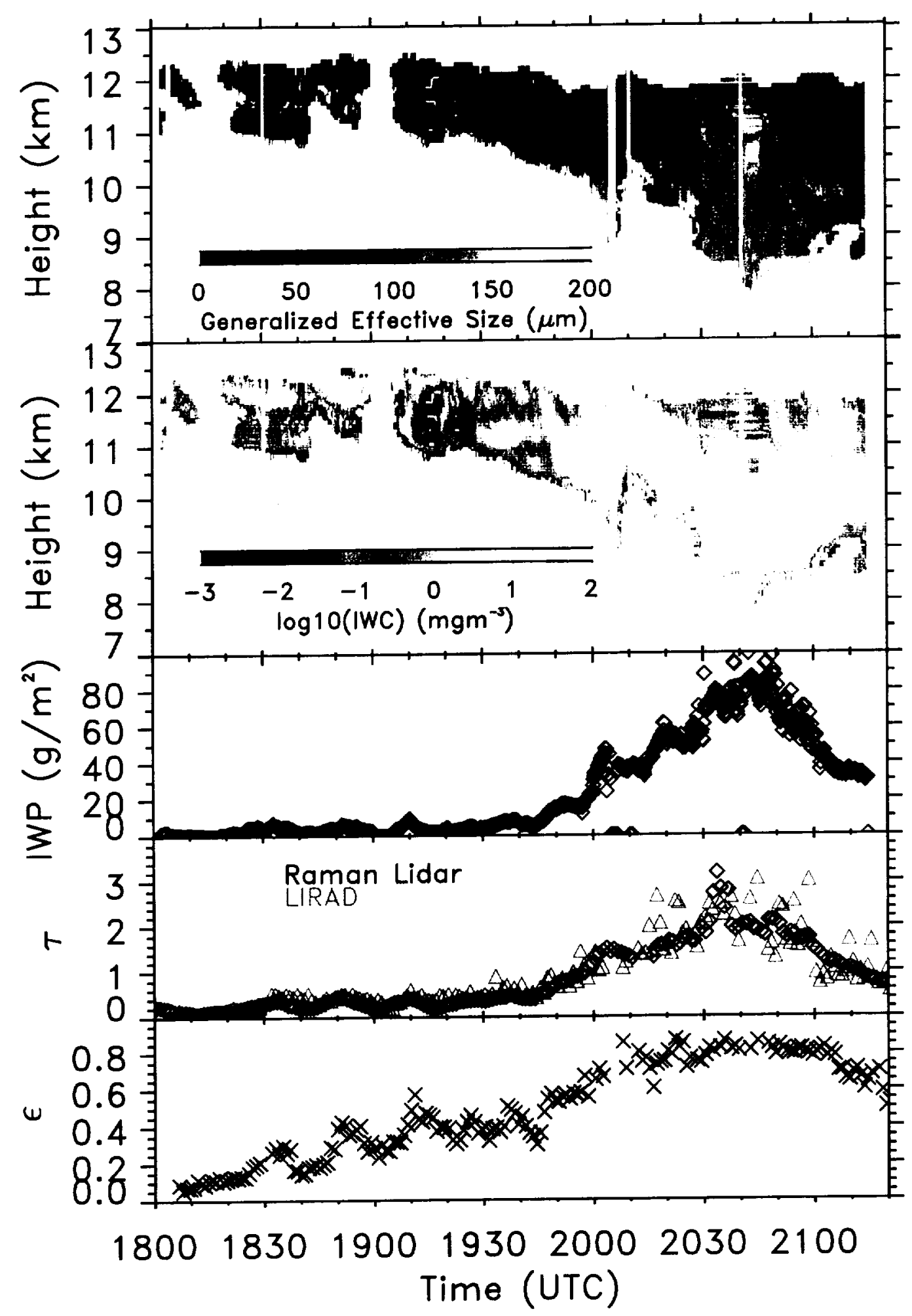

Fig. 6 


\title{
POPULAR SUMMARY
}

\section{Midlatitude Cirrus Clouds Derived from Hurricane Nora: A Case Study with Implications for Ice Crystal Nucleation and Shape}

\author{
Kenneth Sassen ${ }^{1,2}$, W. Patrick Arnott ${ }^{3}$, David O'C. Starr ${ }^{4}$, \\ Gerald G. Mace ${ }^{1}$, Zhien Wang ${ }^{1,5}$, and Michael R. Poellot ${ }^{6}$
}

1. Department of Meteorology, University of Utah, Salt Lake City, Utah

2. Current Affiliation: University of Alaska Fairbanks, Fairbanks, Alaska

3. Desert Research Institute, Reno, Nevada

4. NASA Goddard Space Flight Center, Greenbelt, Maryland

5. Current: University of Maryland Baltimore County, Baltimore Maryland

6. Atmospheric Sciences Dept., Univ. of North Dakota, Grand Forks, North Dakota

This paper provides a detailed analysis of remote sensing observations from ground-based sensors and airborne in-situ measurements focused on the microphysical development of cirrus clouds associated with outflow from Hurricane Nora. Hurricane Nora traveled up the Baja Peninsula coast in the unusually warm El Nino waters of September 1997, until rapidly decaying as it approached Southern California on 24 September. The anvil cirrus blowoff from the final surge of tropical convection became embedded in subtropical flow that advected the cirrus across the western US, where it was studied from the Facility for Atmospheric Remote Sensing (FARS) in Salt Lake City, Utah. A day later, the cirrus shield remnants were redirected southward by midlatitude circulations into the Southern Great Plains, providing a case study opportunity for the research aircraft and ground-based remote sensors assembled at the Clouds and Radiation Testbed (CART) site in northern Oklahoma. Using these comprehensive resources and new remote sensing cloud retrieval algorithms, the microphysical and radiative cloud properties of this unusual cirrus event are uniquely characterized.

Importantly, at both the FARS and CART sites, these cirrus generated spectacular optical displays, which acted as a tracer for the hurricane cirrus, despite the limited lifetimes of individual ice crystals. Lidar depolarization data indicate widespread regions of horizontal ice plate orientations, and in-situ particle replicator data show a preponderance of pristine, solid hexagonal plates and columns. It is suggested that these unusual aspects are the result of the mode of cirrus particle nucleation, presumably involving the lofting of sea-salt nuclei in thunderstorm updrafts into the upper troposphere. This created a reservoir of haze particles that continued to produce halide-salt-contaminated ice crystals during the extended period of cirrus cloud maintenance. The inference that marine microbiota are embedded in the replicas of ice crystals collected over the CART site points to the longevity of marine effects. Various nucleation scenarios proposed for cirrus clouds based on this and other studies, and the implications for understanding cirrus radiative properties on a global scale, are discussed. 
